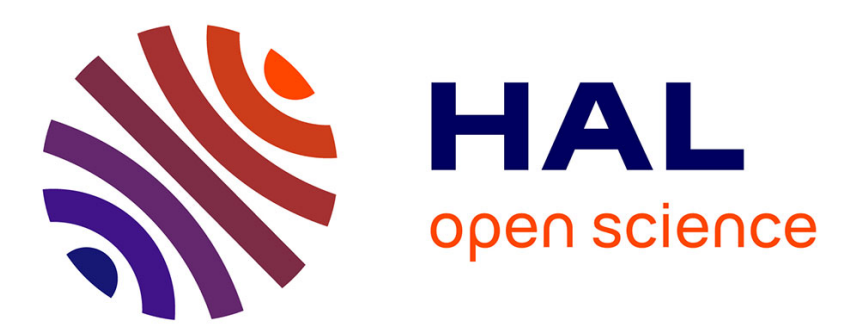

\title{
Numerical and experimental study of expiratory flow in the case of major upper airway obstructions with fluid-structure interaction
}

Franz Chouly, Annemie van Hirtum, Pierre-Yves Lagrée, Xavier Pelorson, Yohan Payan

\section{To cite this version:}

Franz Chouly, Annemie van Hirtum, Pierre-Yves Lagrée, Xavier Pelorson, Yohan Payan. Numerical and experimental study of expiratory flow in the case of major upper airway obstructions with fluid-structure interaction. Journal of Fluids and Structures, 2008, 24 (2), pp.250-269. 10.1016/j.jfluidstructs.2007.08.004 . hal-00260972

\section{HAL Id: hal-00260972 \\ https://hal.science/hal-00260972}

Submitted on 5 Mar 2008

HAL is a multi-disciplinary open access archive for the deposit and dissemination of scientific research documents, whether they are published or not. The documents may come from teaching and research institutions in France or abroad, or from public or private research centers.
L'archive ouverte pluridisciplinaire HAL, est destinée au dépôt et à la diffusion de documents scientifiques de niveau recherche, publiés ou non, émanant des établissements d'enseignement et de recherche français ou étrangers, des laboratoires publics ou privés. 


\title{
Numerical and experimental study of expiratory flow in the case of major upper airway obstructions with fluid-structure interaction
}

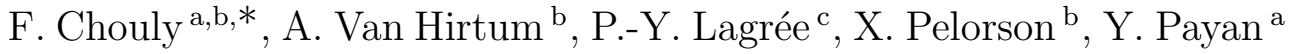 \\ a Laboratoire TIMC, UMR CNRS 5525, Université Joseph Fourier, 38706 La Tronche, France \\ b Département Parole et Cognition, GIPSA-lab, INPG / UMR CNRS 5216, 46 Av. Felix Viallet, 38031 Grenoble, France. \\ c Institut Jean le Rond d'Alembert, UMR CNRS 7190, 4, Place Jussieu, 75252 Paris Cedex 05, France.
}

\begin{abstract}
The presented study deals with the numerical prediction and the experimental description of the flow-induced deformation in a rapidly convergent-divergent geometry which stands for a simplified tongue, in interaction with an expiratory airflow. An original in-vitro experimental model is proposed, that allows measurement of the deformation of the artificial tongue, in condition of major initial airway obstruction. The experimental model accounts for asymmetries in geometry and tissue properties which are two major physiological upper airway characteristics. The numerical method for prediction of the fluid-structure interaction is described. The theory of linear elasticity in small deformations has been chosen to compute the mechanical behaviour of the tongue. The main features of the flow are taken into account using a boundary layer theory. The overall numerical method entails finite element solving of the solid problem and finite differences solving of the fluid problem. First, the numerical method predicts the deformation of the tongue with an overall error of the order of $20 \%$, which can be seen as a preliminary successful validation of the theory and simulations. Moreover, expiratory flow limitation is predicted in this configuration. As a result, both the physical and numerical models could be useful to understand this phenomenon reported in heavy snorers and apneic patients during sleep.
\end{abstract}

Key words: upper airway, fluid-structure interaction, finite element modelling, boundary layer theory, numerical simulation, in-vitro experiment, expiratory flow limitation, snoring, obstructive sleep apnea.

\footnotetext{
* Corresponding author.

Email addresses: franz.chouly@imag.fr (F. Chouly), annemie.vanhirtum@gipsa-lab.inpg.fr (A. Van Hirtum), lagree@jussieu.ccr.fr (P.-Y. Lagrée), xavier.pelorson@gipsa-lab.inpg.fr (X. Pelorson), yohan.payan@imag.fr (Y. Payan).
} 


\section{Introduction}

The upper airway, which encloses the nasal cavity, the pharynx, the mouth and the larynx (fig. 1), is the most external part of the respiratory system. Modelling the fluid flow and the fluid-structure interactions in the upper airway has received a growing interest due to its potential impact in the medical field. Different contributions have been published, such as mathematical models of the interaction between the airflow and the soft tissue (Auregan and Meslier, 1993; Gavriely and Jensen, 1993; Fodil et al., 1997; Huang and Ffowcs Williams, 1999; Aittokallio et al., 2001; Aittokallio and Polo, 2002; Woodson, 2003; Fodil et al., 2005), predictions of the flow-induced vibrations for snoring (Auregan and Depollier, 1995; Huang, 1995; Balint and Lucey, 2005), numerical simulations of the respiratory fluid flow (Shome et al., 1998; Allen et al., 2004; Xu et al., 2006; Sung et al., 2006; Liu et al., 2007) and numerical simulations of the fluid-structure interaction (Payan et al., 2002; Malhotra et al., 2002; Massiot, 2004; Xu, 2005; Huang et al., 2005a,b). Indeed, they give a new insight in the understanding of pathologies such as snoring or obstructive sleep apnea, which is useful, if not necessary, to improve the interaction with the patient, the quality of the treatments and the development of future surgical procedures.

Within the last years, the obstructive sleep apnea syndrome has received much more attention as it has become now a major health care topic, affecting $2 \%$ to $4 \%$ of the adults (Young et al., 1993) and has many consequences such as excessive daytime sleepiness or hypertension (Malhotra and White, 2002). It consists basically in brief and periodic episodes of soft tissue collapse within the upper airway during sleep (Ayappa and Rapoport, 2003; Flemons, 2002; Malhotra and White, 2002; Walsh et al., 1972; Remmers et al., 1978; Deegan and McNicholas, 1995). The collapse in response to inspiratory flow can be partial with flow limitation, which is a hypopnea, or total with flow cessation, which is an apnea. The main features of this physical phenomenon are well explained by models constituted of one collapsible segment in interaction with a fluid: the Starling resistor (Smith et al., 1988; Krieger et al., 1998), the mass-spring models of Gavriely and Jensen (1993) and of Auregan and Meslier (1993).

The modelling of expiratory flow is much less dealt with in literature since the flow pattern is assumed to be normal when there is no more intraluminal negative pressure in the upper airway. Nevertheless, some medical studies have reported expiratory flow limitation during sleep in heavy snorers and in apneic patients (Martin et al., 1980; Sanders and Moore, 1983; Stănescu et al., 1996; Lofaso et al., 1998; Woodson, 2003). As it has been explained in (Lofaso et al., 1998), this can not be understood using the Starling resistor model. It has been shown that a model constituted of at least two independent segments, described for instance in (Fodil et al., 1997), is able to reproduce it (Lofaso et al., 1998). This is an important first step, but further analysis should be requiered in so far as the mechanisms of airway collapse and of subsequent flow limitation are expected to be completely different in inspiration and expiration (Woodson, 2003). Each respiratory phase is indeed associated to very particular conditions in the upper airway (boundary conditions of the flow, change of geometry and of activation of the muscles).

The aim of this paper is to present a theoretical study combined to an experimental study of the fluidstructure interaction which occurs during expiration in conditions of major airway obstruction at the base of the tongue. This latter condition should be expected in most of the apneic patients or snorers as their upper airway is narrower than those of normal subjects (Ayappa and Rapoport, 2003; Schwab et al., 2003). A numerical model based on continuum mechanics is used to give a more detailed description of the mechanisms that occur in such conditions. An in-vitro deformable tongue replica enables direct observation and measurement of the flow-induced deformation as well as the validation of the numerical predictions.

Firstly, the theory on which the numerical model is based is presented. The particular conditions investigated allow us to consider simplificatory assumptions. As a result, the computation time for a simulation is significatively reduced. Next, the in-vitro set-up is described. It has been designed to be more appropriate than the Starling resistor to study the upper airway in pathological conditions implying an important initial 
obstruction (such as obesity or tongue pathology (Fogel et al., 2004)) . The particular assumptions as well as the numerical method are validated using this set-up, through the comparison of the measured and predicted flow-induced deformation of the tongue replica. The observations that result from the numerical simulations give a new insight in the phenomena that happen during expiration in this particular configuration. Furthermore, it will be shown that the Bernoulli theorem is helpful to give a qualitative explanation of the flow features. Finally, the influence of the mechanical parameters which have an anatomical or physiological meaning is studied.

\section{Theoretical assumptions and methods}

\subsection{Description of the walls}

Models of the upper airway such as (Auregan and Meslier, 1993; Gavriely and Jensen, 1993; Fodil et al., 1997) consider its wall as made of one or two independent compliant segments, governed by equations of general form:

$$
A_{i}=f\left(p_{i}\right),
$$

where $A_{i}$ is the sectional area of the fluid channel at segment $i$ and $p_{i}$ is the transmural pressure at the level of the segment $i$, with $i \in\{1,2\}$. $f$ is a state function. Assuming that the state function is linear, the segment acts like a spring since $f(x)=k^{-1} x, k$ being the stiffness coefficient of the spring. However, such a simple description might not be sufficient to reproduce accurately the highly complex behaviour of the upper airway soft tissue, especially in the context of a realistic prediction. A more appropriate representation of the soft tissue would be to consider it as a continuous medium, in which the relationship between local deformation and local constraint is computed everywhere. As a result, continuum mechanics has been chosen as a framework for this study (Bonet and Wood, 1997). In addition, two assumptions have been formulated so as to simplify the mechanical problem. It is firstly supposed that inertia forces are negligible, which is a quasi-static assumption: only motions of the soft tissue of characteristic time of the order of a few seconds are considered. The assumption of small deformations is also made: the deformation from rest position is supposed not to exceed $15 \%$, so that second order terms can be dropped from the Green-Lagrange strain tensor $\mathbf{E}$, to obtain the small deformations tensor $\varepsilon$. Since the material is supposed to be linear, isotropic and homogeneous, the elastic Hookean law is sufficient to describe its constitutive properties

$$
\boldsymbol{\sigma}=\frac{E \nu}{(1-2 \nu)(1+\nu)} \operatorname{tr}(\varepsilon) \mathbf{I}+\frac{E}{1+\nu} \varepsilon
$$

where $\mathbf{I}$ is the identity tensor, $\operatorname{tr}(\varepsilon)$ is the first invariant of the small deformations tensor, $E$ is the Young modulus, $\nu$ is the Poisson's ratio (Bellet and Barrau, 1990). These assumptions could appear as too restrictive compared to models of fluid-structure interaction in a channel presented in the literature. Shapiro (1977) and Cancelli and Pedley (1985) apply a strongly non-linear functional "tube law", while Luo and Pedley (1995); Heil and Pedley (1996); Hazel and Heil (2003) describe even more complex non-linear membrane or shell equations to account for large wall deformations. Nevertheless, as pointed out in the introduction, the main objective of this work is to study conditions of major airway obstruction, in which small deformations combined with linear elasticity should be sufficient as a first approximation. The chosen numerical tool for computations is the finite element method (Zienkiewicz and Taylor, 1989). Once the mesh is defined, the best approximation of the solution is obtained from the determination of nodal displacements that minimize the total potential energy of the structure. This variational formulation of an elasticity problem is detailed in (Zienkiewicz and Taylor, 1989). From nodal displacements, values of the small deformations tensor $\varepsilon$ and of the stress tensor $\boldsymbol{\sigma}$ are established at each point of the structure as the aim of the finite element method is to provide a continuous approximation. Under the assumption of small deformations, and with the quasi-static 
hypothesis, it can be demonstrated (Zienkiewicz and Taylor, 1989) that the required nodal displacements are obtained from solving a linear system

$$
[\mathbf{K}]\{\mathbf{u}\}=\{\mathbf{F}\},
$$

where $\{\mathbf{u}\}$ is the vector of nodal displacements, $\{\mathbf{F}\}$ is the vector of external forces applied to each node and $[\mathbf{K}]$ is the stiffness matrix, obtained from integration of the constitutive law (2) on each element (Zienkiewicz and Taylor, 1989). The computation of $\{\mathbf{F}\}$ is detailed in section 2.3. The displacement vector is decomposed as following: $\{\mathbf{u}\}=\left\{\mathbf{u}_{\mathbf{f}} \mathbf{u}_{\mathbf{c}}\right\}^{T}$ where $\mathbf{u}_{\mathbf{f}}$ is constituted of all degrees of freedom, and $\mathbf{u}_{\mathbf{c}}$ of all constrained displacements. The vector of free displacements $\left\{\mathbf{u}_{\mathbf{f}}\right\}$ is given by

$$
\left\{\mathbf{u}_{\mathbf{f}}\right\}=[\mathbf{M}]\{\mathbf{F}\}+\left\{\mathbf{u}_{\mathbf{f}}^{*}\right\},
$$

where $[\mathbf{M}]$ matrix is derived from the stiffness matrix $[\mathbf{K}]$ after simple algebra (Imbert, 1991), and will be named the compliance matrix. $\left\{\mathbf{u}_{\mathbf{f}}{ }^{*}\right\}$ is a displacement vector induced by constant constraints in force and in displacement. So as to compute the $[\mathbf{M}]$ matrix, a commercial finite element solver (Ansys(TM) Software) has been employed, which ensures high reliability and accuracy of computations. However, it does not allow straightforward computation of this matrix. So, a method similar to the one described in (Cotin et al., 1999) permits the precomputation of the $[\mathbf{M}]$ matrix and of the $\left\{\mathbf{u}_{\mathbf{f}}{ }^{*}\right\}$ vector. Furthermore, it avoids carrying out a complete structural analysis at each iteration of the main loop of the fluid-structure coupling algorithm, which saves significant computation time. The precomputation method is described in Appendix A.

\subsection{Description of the airflow}

Characteristics of flow circulation within a constriction have been studied extensively, for instance in the glottis (Scherer and Titze, 1983; Scherer et al., 2001; Hofmans et al., 2003; Pelorson et al., 1995), in a stenosis (Berger and Jou, 2000) or in the pharynx (Shome et al., 1998; Allen et al., 2004; Xu et al., 2006; Sung et al., 2006; Liu et al., 2007). From these studies, a schematic description of the flow is illustrated in

fig. 2. While entering in constriction, the fluid is submitted to acceleration due to the constant flow rate. After the narrowest part of the constriction, it tends to decelerate and to separate from walls, so as to form a wall-bounded jet (fig. 2).

In (Van Hirtum et al., 2005), different models have been compared to experimental measurements from an in-vitro set-up. The choice of the model described in this section results directly from this comparison and is briefly described in the following. At first approximation, the flow is supposed to be laminar, as the turbulent effects due to shear instability in the jet should be neglected. Indeed, these effects appear far downstream the constriction, and should have no significant influence on the soft tissue. The validity of this assumption is confirmed by the experimental study (Van Hirtum et al., 2005). Moreover, the flow is assumed to be quasisteady, incompressible and two-dimensional (Van Hirtum et al., 2005). In this context, the fluid model is derived from simplifications of the Navier-Stokes (5) and continuity (6) equations

$$
(\boldsymbol{v} \cdot \operatorname{grad}) \boldsymbol{v}=-\frac{1}{\rho} \operatorname{grad} P+\nu \nabla^{2} \boldsymbol{v}
$$

$$
\operatorname{div} \boldsymbol{v}=0,
$$

where $P$ is pressure, $\rho$ is density, $\nu$ is kinematic viscosity, $\boldsymbol{v}$ is local velocity. With the help of two other supplementary assumptions, which are channel transversal dimension $h_{0}$ smaller than its longitudinal dimension $D$ (fig. 2) and high Reynolds number $\operatorname{Re}=U_{0} h_{0} / \nu$ ( $U_{0}$ is the mean longitudinal speed), the Navier-Stokes (5) and continuity (6) equations can be simplified so as to obtain Reduced Navier-Stokes / Prandtl (RNS/P) equations (Lagrée et al., 2005) 


$$
\begin{aligned}
\bar{u} \partial_{\bar{x}} \bar{u}+\bar{v} \partial_{\bar{y}} \bar{u} & =-\partial_{\bar{x}} \bar{p}+\partial_{\bar{y}^{2}}^{2} \bar{u}, \\
-\partial_{\bar{y}} \bar{p} & =0, \\
\partial_{\bar{x}} \bar{u}+\partial_{\bar{y}} \bar{v} & =0,
\end{aligned}
$$

where all variables are nondimensional : $\bar{x}=x\left(h_{0} R e\right)^{-1}, \bar{y}=y h_{0}^{-1}, \bar{p}=P\left(\rho U_{0}^{2}\right)^{-1}, \bar{u}=u U_{0}^{-1}, \bar{v}=$ $v R e U_{0}^{-1}$. $(u, v)$ are longitudinal and transverse components of the velocity $\boldsymbol{v}$ (Van Hirtum et al., 2005; Lagrée et al., 2005). Boundary conditions consist in no slip on the lower and upper walls (Van Hirtum et al., 2005). For a flow within a constriction, RNS/P equations (7) are appropriate to describe the effects of viscosity, in particular the formation of a boundary layer (Schlichting, 1979). From the RNS/P equations, the computation of the wall shear stress $\tau_{\text {wall }}$ is used as a criterion to determine the position $x_{s}$ of fluid separation from walls, where it vanishes

$$
\tau_{\text {wall }, x_{s}}=\left.\rho \nu \frac{\partial u}{\partial y}\right|_{x_{s}, y_{\text {wall }}}=0 .
$$

The accuracy of such prediction has extensively been studied in (Van Hirtum et al., 2005), compared to other prediction theories such as 1D inviscid flow or 2D boundary layer. This set of equations is solved using finite difference method with a regular grid (Lagrée et al., 2005; Cousteix, 1988). A vector $p\left[x_{i}^{p}\right]_{i=1, \ldots, n_{\max }}$, which represents the pressure distribution all along a two-dimensional channel, is then obtained. $\left[x_{i}^{p}\right]_{i=1, \ldots, n_{\max }}$ is the abscissa of each grid point where the pressure is computed. The wall shear stress $\tau\left[x_{i}^{p}\right]_{i=1, \ldots, n_{\max }}$ is also obtained by numerical resolution. Computations in a rigid channel indicate that the magnitude of the wall shear stress is negligible compared to the yielded pressure values (Chouly, 2005). In practice, a grid of $2000 \times 1000$ points, in respectively $x$ and $y$ direction, has been used. Numerical experiments showed that at least $1000 \times 500$ points were necessary to obtain a satisfactory prediction of the pressure distribution (with less than $1 \mathrm{~Pa}$ of overall difference for higher grid resolutions).

\subsection{Computation of fluid forces}

For an element $(e)$, the only way to compute the deformation from the pressure distribution on the element frontier $l$ is to determine nodal forces equivalent to pressure. This is achieved by use of the virtual work theorem

$$
\left\{\mathbf{F}_{\text {nodes }}^{(e)}\right\}=W \int_{l}[\mathbf{N}(\mathbf{x})]^{t} p(\mathbf{x})\{\mathbf{n}(\mathbf{x})\} d l
$$

where $\left\{\mathbf{F}_{\text {nodes }}^{(e)}\right\}$ is the vector of equivalent nodal forces and $W$ the depth of the bidimensional element. For a point $\mathbf{x}$ in the frontier $l$ of $(e),[\mathbf{N}(\mathbf{x})]$ is the interpolation matrix, $p(\mathbf{x})$ is the pressure and $\{\mathbf{n}(\mathbf{x})\}$ is the normal vector to the frontier (fig. 3 (a)) (Zienkiewicz and Taylor, 1989; Bonet and Wood, 1997). For a quadrilateral element of four nodes, with the local coordinate system $(s)$ shown in fig. $3(\mathrm{~b})$, the expression (9) can be simplified in

$$
\left\{\mathbf{F}_{\text {nodes }}^{(e)}\right\}=\left(\int_{-1}^{1}[\mathbf{N}(s)]^{t} p(s) d s\right) \frac{\{\mathbf{a}\}}{2},
$$

where 


$$
\mathbf{a}=W\left\|\mathbf{x}_{1}-\mathbf{x}_{-\mathbf{1}}\right\| \mathbf{n}
$$

is the area vector associated to the element, $\mathbf{x}_{-\mathbf{1}}, \mathbf{x}_{\mathbf{1}}$ being element nodes (fig. 3 (b)). For a discrete pressure distribution $p\left[s_{i}\right]_{i=1, \ldots, n}$ associated to an appropriate subdivision $\left[s_{i}\right]_{i=1, \ldots, n+1}$ of the element frontier, it can be shown that for each node $(k)$, where $k \in\{-1,1\}$ stands for node of coordinates $\mathbf{x}_{k}$, the equivalent force is

$$
\left\{\mathbf{F}_{k}^{(e)}\right\}=\left(k \sum_{i=1}^{n} p\left[s_{i}\right] \omega\left(k s_{i}, k s_{i+1}\right)\right) \frac{\{\mathbf{a}\}}{4}
$$

with

$$
\omega(x, y)=\frac{1}{2}(y-x)(2+x+y)
$$

The calculation of (12) is detailed in Appendix B. Then, the pressure force on each node of the mesh is the resultant of all the contributions of forces from adjacent elements, which allows to compute the vector $\{\mathbf{F}\}$ of external forces due to the fluid pressure (standard assembly procedure of the finite element method).

For the wall shear stress, the method is rigorously the same. It has been taken into account by replacing in the above formulas the discrete pressure distribution $p\left[s_{i}\right]$ by the discrete shear stress distribution $\tau\left[s_{i}\right]$ and by transformation of the vector a into a vector $\mathbf{d}$ tangent to the streamlines and oriented downstream.

\subsection{A fluid-structure coupling algorithm}

Both mechanical models of structure and fluid need to be in interaction. This is achieved by use of a general iterative fluid-structure coupling algorithm summarized in fig. 4. The behaviour (structure deformation, flow characteristics) of the model is predicted for an initial condition: a given pressure drop $\Delta P$ between the inlet and the outlet of the fluid channel. It is increased step by step: $\Delta P_{1}=0, \ldots, \Delta P_{n_{\text {steps }}}=\Delta P$ where $n_{\text {steps }}$ is the number of steps.

For each step $i$, a given pressure drop $\Delta P_{i}=P_{\mathrm{in}, i}-P_{\mathrm{out}, i}$ is imposed, through change of the pressures $P_{\text {in }, i}$ at the inlet and $P_{\text {out }, i}$ at the outlet. The geometry of the channel is obtained from the structure, after deformation at step $i-1$. The pressure and wall shear stress distribution in the channel are first computed, according to the method described in section 2.2. Thus, forces applied to the walls are determined, as explained in section 2.3. The resulting deformation of the walls is predicted using the description of section 2.1 (equation (4)). This deformation induces new boundary conditions. As a result, a new prediction of the flow has to be computed from which a new deformation of the walls is obtained. The algorithm keeps on iterating until a fixed number of iterations $n_{\text {iterations }}$ is reached. The convergence is measured thanks to a convergence criterion $\varepsilon$ which corresponds to the maximal nodal displacement between two successive iterations:

$$
\varepsilon=\max _{j \in N}\left\|\mathbf{u}_{i}^{j}\right\|
$$

where $i$ is the index of the iteration and $\mathbf{u}_{i}^{j}$ the displacement vector of the node $j$ from iteration $i$ to $i+1$. $N$ is the number of nodes in the mesh. With a correct choice for $n_{\text {iterations, }}$ the value of $\varepsilon$ is lower than a given threshold, typically of $10^{-4} \mathrm{~mm}$ (fig. 10 (c) and fig. 12 (c)), and equilibrium is then reached (quasi-steady hypothesis). In practice, a choice of $n_{\text {iterations }}=6$ was found to be sufficient to ensure convergence. At the end of the loop, the step is increased from $i$ to $(i+1)$. 


\section{In-vitro set-up}

The pharyngeal airway has a highly complex anatomical structure which can be roughly divided into main entities such as the tongue, the soft palate, the uvula and the pharyngeal walls. These soft tissue are mostly composed of muscles and fat deposits. Some bony structures are present as insertions for muscles: mandibulae, hard palate, hyoid bone (fig. 1). More than twenty upper airway muscles are thought to influence the diameter of the pharyngeal lumen (Ayappa and Rapoport, 2003). Though a very realistic anatomical and mechanical model of the upper airway would be the best solution for accurate simulation, for the sake of simplicity, our modelling approach will be validated at first on an idealized geometry. So, the main goal of the in-vitro set-up is to reproduce a fluid-structure interaction within a constriction, from which observations and measurements could be obtained in order to allow quantitative comparison with simulations predicted from the theoretical model. The constriction represents roughtly the geometry of the upper airway near the base of the tongue. First, the in-vitro set-up is briefly described in section 3.1. Then, a finite element model of the deformable wall of the set-up is presented in section 3.2.

\subsection{Description}

The set-up under study is depicted in fig. 5. It consists of a cylinder attached to a rigid pipe, which delimits a channel for the airflow. For a first approximation, the cylinder can be considered to play the role of the tongue and the rigid pipe to represent the trachea and the posterior pharyngeal wall (fig. 6). The cylinder can either be rigid (metallic) or deformable (thin latex tube filled with water). The use of a rigid cylinder is a necessary first step as it allows very accurate measures of fluid characteristics (velocity, pressure) which are fully described in (Van Hirtum et al., 2005). The deformable latex cylinder is used as a second step for observations of flow-induced deformation. It is glued to the rigid pipe using silicon. At the beginning of each experiment, the latex is at rest, without initial tension. The diameter $D$ of the latex tube is $49 \mathrm{~mm}$. The internal diameter $d$ of the rigid pipe is $25 \mathrm{~mm}$. The thickness $l_{t}$ of the latex is $0.3 \mathrm{~mm}$. The initial height $h_{c}$ at the location of the constriction is the main geometrical parameter. It can be changed by adding or removing metallic plates (fig. 5 (a)). The heights $h_{c}$ could therefore be ranged from $0 \mathrm{~mm}$ up to $2 \mathrm{~mm}$. As $d$ is of 25 $\mathrm{mm}$, it induces an initial obstruction ratio which is between $92 \%$ (for $h_{c}$ of $2 \mathrm{~mm}$ ) and $100 \%$ (for $h_{c}$ of 0 $\mathrm{mm}$ ). This corresponds to major initial obstruction of the upper airway, which should be expected in some snorers or apneic patients that have a narrower pharyngeal duct because of fatter soft tissue (Schwab et al., 2003) or particular bone configuration (Fogel et al., 2004; Sforza et al., 2000). The maximal value for $h_{c}(2$ $\mathrm{mm}$ ) is smaller than the values reported in cephalometric studies on real patients for the minimal pharyngeal opening in rest position. Indeed, these are typically of $6 \mathrm{~mm}$ behind the soft-palate and of $11 \mathrm{~mm}$ behind the tongue (Sforza et al., 2000). Nevertheless, these values are measured while the subject is awake and is standing. During sleep, and in supine position, these values are likely to become smaller due to the action of gravity combined to a decrease of the neuromuscular activation. In a preliminary study, an estimation of this decrease, based on computations from 2D radiographies, has been carried out (Chouly et al., 2006). The minimal pharyngeal opening behind the tongue obtained from these estimations is between $1 \mathrm{~mm}$ and $2 \mathrm{~mm}$, and is therefore the one used in this set-up.

Finally, a pressure tap was drilled in the rigid pipe upstream of the tongue replica in order to measure the pressure drop $\Delta P$ (fig. 5 (a)).

\subsection{Finite element model of the deformable wall}

Within the framework described in section 2.1, a finite element three-dimensional model of the latex tube, which is the only deformable part of the in-vitro set-up, has been designed, in agreement with both its geometry and its mechanical properties: constitutive mechanics and boundary conditions (fig. 7). The choice 
of a two-dimensional model would have prevented taking into account mechanical boundary conditions (zero displacement) with accuracy (fig. 7 (b)). Water inside this thin latex wall has been taken into account by applying constant pressure forces on elements, which is consistent with the in-vitro set-up. As the fluid model is assumed to be two-dimensional and the structural model is three-dimensional, the structure is divided into slices of small thickness. From the fluid simulation on each slice, a pressure distribution is computed for each element. The number of slices for all the simulations has been fixed to 5 (fig. 7 (a)). So as to measure the impact of this numerical parameter, another model with 10 slices has been built. No difference with the model with 5 slices has been detected while carrying out the simulations. The model is built from hexahedra, which are three-dimensional eight nodes elements. Mesh regularity and good stability properties of hexahedra ensure a correct approximation of the solution. As the Poissons's ratio value $(\nu=0.499 \simeq 0.5)$ is imposed by incompressibility, the only mechanical parameter of the model to fix is the Young modulus $E$.

\section{Results and discussion}

First, in section 4.1, a method to determine the Young modulus $E$ of the latex tube is described. Then, numerical simulations using the method described in section 2 and the finite element model presented in section 3.2 are carried out and compared to experiments in section 4.2. Finally, the influence of the model parameters is discussed in section 4.3 .

\subsection{Assessment of mechanical characteristics}

Before proceeding to simulation of the fluid/wall interaction, the mechanical properties of the latex tube that belongs to the in-vitro set-up have to be determined. It will ensure consistent comparisons in the second stage. In order to estimate the value of the Young modulus $E$, a preliminary experiment has been carried out. A complete experimental protocol of rheology measurement would have been necessary to evaluate $E$ with accuracy. Yet, many of the existing protocols are not compatible with the specific configuration of the in-vitro set-up. As a result, the method applied consisted in determining the wall deformation in response to the external pressure variation induced by water, using simulation and experiment.

Experimentally, the external pressure $P_{\text {ext }}$ of water inside the latex tube has been changed and measured, while the fluid flow was at rest within the rigid pipe $(\Delta P=0)$. The deformation induced by this change has been evaluated through the constriction height $h_{c}$ in the middle section. Indeed, as the external pressure $P_{\text {ext }}$ is increased, $h_{c}$ decreases as the thin latex wall is deformed. Thus, $h_{c}$ is a function of $P_{\text {ext }}$ and of the Young modulus $E$ :

$$
h_{c}=h_{c}\left(P_{\text {ext }}, E\right)
$$

The value of the height $h_{c}$ when the set-up is at rest $\left(P_{\text {ext }}=0\right)$ will be named $h_{c}^{\text {rest }}$ :

$$
h_{c}^{\text {rest } \stackrel{\text { def }}{=}} h_{c}\left(P_{\text {ext }}=0\right) \text {. }
$$

It is no longer dependent of $E$ and its value depends only of the geometry of the set-up. During the experiment, the height $h_{c}\left(P_{\text {ext }}\right)$ has been determined indirectly by measuring the intensity change of a laser beam (fig. 5 (a)). The calibration of the optical device was made against calibrated holes. Typical accuracy for $h_{c}$ is of order of $10^{-2} \mathrm{~mm}$. The experimentally set initial conditions have been reproduced in the simulations, by imposing constant forces on the external nodes, equivalent to a pressure $P_{\text {ext }}$ on surfaces of the elements. The 
constriction height $h_{c, \text { num }}\left(P_{\text {ext }}\right)$ after deformation in the middle section has been computed and compared to the experimental value $h_{c, \exp }\left(P_{\text {ext }}\right)$.

In fig. 8 , both experimental and computed curves $h_{c}=h_{c}\left(P_{\text {ext }}\right)$ are superimposed. Note that for values of $P_{\text {ext }}$ higher than $2100 \mathrm{~Pa}$, the latex tube is in contact with the floor of the rigid pipe and $h_{c}$ is no longer decreasing. From the experimental curve, a non-linear mechanical behaviour of the latex cylinder can be observed. Nevertheless, as a first approximation, the relationship might be linearized. The computed curves are linear, which is due to small deformations hypothesis and assumption of a linear relationship between constraint and deformation, with slope proportional to the inverse of the Young modulus $E$. Least square estimation leads to a value of the Young modulus $E \simeq 1.6 \mathrm{MPa}$. It is consistent with values for latex materials available in the literature (Treloard, 1975).

\subsection{Simulation of the flow-induced deformation}

In order to study the in-vitro behaviour of the latex wall in response to a fluid flow circulation, the following experiment has been carried out: for a given value of the external pressure $P_{\text {ext }}$ and of the initial constriction height $h_{c}\left(P_{\text {ext }}\right)$, a pressure drop $\Delta P$ has been imposed gradually between the inlet and the outlet of the rigid pipe. The pressure at the inlet has been increased from 0 to $\Delta P$ and the pressure at the outlet has been considered constant and equal to $0 \mathrm{~Pa}$, which corresponds to expiratory conditions. The evolution of the constriction height $h_{c}$ has been measured through the intensity change of a laser beam (as explained in section 4.1). Its initial value $h_{c}^{\text {init }}$ is measured also with the laser beam after $P_{\text {ext }}$ has been imposed. The deformation of the walls has been simulated, using the same parameters as those chosen for the experiment. A curve $\Delta h_{c, \text { comp }}(\Delta P)$ is then obtained, which allows quantitative comparison with the experimental data. A typical example (no. 1) is illustrated in fig. 9 and fig. 10 for a constriction height $h_{c}^{\text {init }}$ of $1.20 \mathrm{~mm}$, a pressure drop $\Delta P$ of $200 \mathrm{~Pa}$ and an external pressure $P_{\text {ext }}$ of $200 \mathrm{~Pa}$. Another example (no. 2) is presented in fig. 11 and fig. 12 for a constriction height $h_{c}^{\text {init }}$ of $0.87 \mathrm{~mm}$, a pressure drop $\Delta P$ of $290 \mathrm{~Pa}$, and an external pressure $P_{\text {ext }}$ of $400 \mathrm{~Pa}$. All the results are presented in normalized form. The constants for normalization of each parameter have been chosen as follows : $h_{0}=15 \mathrm{~mm}, h_{c}^{0}=h_{c}^{\text {init }}$ (so $h_{c}^{0}$ is different for the two examples), $v_{0}=10 \mathrm{~m} / \mathrm{s}, P_{0}=100 \mathrm{~Pa}, \Phi_{0}=10 \mathrm{l} / \mathrm{min}$. In both cases, 3 sets of experimental data corresponding to measurements made at different times, are compared to the numerical simulations. The general conclusions that can be drawn from this study are summarized as follows:

For an initial constriction height small enough, an increase of the pressure drop $\Delta P$ results in a decrease of $h_{c}$. This relationship is observed and simulated to be approximately linear. Indeed, while entering the constriction, the airflow is submitted to a strong acceleration (fig. 9 (a) and fig. 11 (a)) because of mass conservation. This acceleration is followed by pressure losses at the level of the constriction (fig. 9 (b) and fig. 11 (b)), which is a natural consequence of the Bernoulli theorem (Venturi effect). The pressure even becomes negative at the level of the constriction, so that the transmural pressure difference $P_{\text {int }}-P_{\text {ext }}$ is locally negative. This explains the decrease of $h_{c}$. However, the moving boundaries of the duct, which follow the deformation of the solid, produce second order effects on the flow features (velocity and pressure) and the acceleration effect due to the strong constriction appears predominant here. After the constriction, the effect of the boundary layers can not be neglected: there is flow separation and the boundary layer, by his displacement effect, reduces the effective width of the constriction, so the Bernoulli theorem is no longer valid. Finally, it can be seen from the simulations that the pressure quickly becomes constant and equal to the value at the outlet (0 Pa here) (Van Hirtum et al., 2005). ${ }^{1}$ Compared with experimental data the simulations appear to be in reasonable agreement. Overall, typical discrepancies are of order of $20 \%$ at the

\footnotetext{
$\overline{1}$ Note that the Bernoulli theorem completed with an ad-hoc geometric criterion for the prediction of the flow separation has been used to derive a simple analytic formula for computation of the pressure distribution inside the duct. Nevertheless, it has revealed to be inappropriate for an accurate prediction of the flow features (Van Hirtum et al., 2005; Chouly, 2005).
} 
most which is quite satisfactory considering the amount of theoretical simplifications involved.

Experimentally, a different kind of regime is observed when the pressure drop $\Delta P$ reaches a critical value. This critical value is a function of both the mechanical characteristics of the tongue replica and of the initial geometrical conditions. It is more than $160 \mathrm{~Pa}$ for the data set 1 of example no. 1, more than $200 \mathrm{~Pa}$ for the data sets 2 and 3 of the example no. 1, and of approximatively $270 \mathrm{~Pa}$ for the data sets of the example no. 2. In this configuration, self-sustained oscillation of the tongue replica initiates. This phenomenon is not simulated numerically because of the quasi-steady assumption. From a pathological point of view, this situation corresponds to snoring event, and is, therefore, not relevant for the current study.

At the end of the simulations, the maximal Von Mises strain associated to the deformation of the wall is of order of $3 \%$, which is in agreement with the small deformations assumption. As a result, it is not necessary for these simulations to solve equations for large deformations, which would increase dramatically the cost of computations. Indeed, the mean computation time for each simulation is of order of ten minutes on a desktop computer. For the both simulations, assesment of the convergence has been done by plotting the evolution of the normalized convergence criterion $\mathrm{cv}=\varepsilon / h_{c}^{0}$ with the iterations for all the steps.

For each of the two simulations presented previously (no. 1 and no. 2), the flow rate has finally been computed and is depicted fig. 13 (a) and (b). For each figure, two curves are superimposed. One is obtained from the simulation of the fluid-structure interaction, while the second one is obtained for the same parameters but with a rigid (undeformable) structure. For the simulation no. 1, a flow limitation of $49.9 \%$ is observed. For the simulation no. 2, the limitation is $69.6 \%$. This phenomenon of expiratory flow limitation due to the flow-induced deformation has already been observed in apneic patients or snorers during sleep (Martin et al., 1980; Sanders and Moore, 1983; Stănescu et al., 1996; Lofaso et al., 1998; Woodson, 2003). The airway obstruction which is at its origin seems to occur more frequently at the base of the tongue (Woodson, 2003). Moreover, the expiratory flow limitation appears to be coupled to inspiratory flow limitation in most of the cases (Stănescu et al., 1996) and is suspected to favour increased obstruction during the following inspiratory breaths (Woodson, 2003). It can not be explained using the Starling Resistor analogy. Indeed, in expiratory conditions, the intraluminal pressure in the resistor is positive. As a result, an increase of the upstream pressure can only be followed by a reopening of the tube and thus an increase of the flow (Lofaso et al., 1998). Instead, a multi-element model of at least two compliant segments has been found sufficient to reproduce this expiratory flow limitation and to give a coherent physical basis for the observed phenomena (Lofaso et al., 1998; Woodson, 2003). Indeed, it can take into account the anatomical and physiological heterogeneities of the upper airway (Fodil et al., 1997). Typically, one segment stands for the oropharynx and the other for the nasopharynx (Lofaso et al., 1998). Each segment can be associated with specific geometrical or mechanical properties (initial position or compliance for instance). In particular, if the cross-sectional area at the level of the oropharyngeal segment is supposed to be smaller than at the level of the nasopharynx (narrowing at the base of the tongue), an increase of the upstream pressure (expiration) will cause a decrease of the minimal cross-sectional area and therefore a limitation of the airflow. As we saw before, the Venturi effect at the level of the narrowing is responsible for the pressure losses inducing this decrease (Lofaso et al., 1998). Far away from refuting the analysis coming from this simple mathematical model, our physical and numerical model conforts it. Moreover, the numerical method provides a more refined prediction of the flow features and of the deformation of the wall.

\subsection{Sensitivity of the model to geometrical and mechanical parameters}

In order to illustrate the potential usefulness of the simulation software, the influence of three important geometrical and mechanical parameters has been studied. The choice of these parameters is led by the physiological interpretation that can be done. These parameters are the initial constriction height, the Young modulus and the external pressure of the water inside the latex tube. The influence of all these parameters is 
evaluated through the computation of the relative constriction height variation

$$
\Delta h_{c}=\frac{h_{c}^{\mathrm{init}}-h_{c}^{\mathrm{def}}}{h_{c}^{\text {init }}},
$$

where $h_{c}^{\text {init }}$ is the initial height, after the external pressure $P_{\text {ext }}$ has been imposed, and $h_{c}^{\text {def }}$ is the height after the deformation induced by the internal flow. All these parameters are presented in normalized form in fig. 14, fig. 15 and fig. 16. The reference values used for normalization are $\Phi_{0}=10 \mathrm{l} / \mathrm{min}$ for the flow rate, $h_{c}^{0}=1 \mathrm{~mm}$ for the constriction height, $E_{0}=1 \mathrm{MPa}$ for the Young modulus and $P_{\mathrm{ext}}^{0}=1000 \mathrm{~Pa}$ for the external pressure.

The first parameter investigated is the initial constriction height $h_{c}^{\text {init }}$, which influence can be observed in fig. 14. The simulations had been carried out for a pressure drop $\Delta P$ of $150 \mathrm{~Pa}$, an external pressure $P_{\text {ext }}$ of $200 \mathrm{~Pa}$ and a Young modulus $E$ of $1.6 \mathrm{MPa}$. The higher is the value of the initial constriction height, and thus the wider is the channel, the less important is the constriction height variation $\Delta h_{c}$, the relationship being non-linear (fig. 14 (a)). Alternatively, the airflow rate increases as the initial constriction height is increased, in an almost linear relationship (fig. 14 (b)). In terms of physiological interpretation, the constriction height corresponds to the minimal pharyngeal caliber, which is well known to be a critical anatomical factor, directly in relationship with the upper airway collapse (Deegan and McNicholas, 1995). The result of fig. 14 seems to be qualitatively in agreement with in-vivo and clinical observations. For instance, Isono et al. (1997) showed that the pharynx of apneic patients was narrower than the pharynx of a reference group. Moreover, an increase of the pharyngeal caliber corresponds to a decrease of apnea or hypopnea frequency and severity. In expiratory conditions, a narrower pharynx should also favour a collapsus of greater amplitude, with increased flow limitation, since it increases the Venturi effect at the level of the constriction.

The second parameter examined was the Young modulus $E$ of the latex tube. Simulations were carried out with a pressure drop $\Delta P$ of $150 \mathrm{~Pa}$, an external pressure $P_{\text {ext }}$ of $200 \mathrm{~Pa}$ and an initial constriction height $h_{c}^{\text {init }}$ of $1.5 \mathrm{~mm}$. $E$ has been chosen within a range of values that went from $0.4 \mathrm{MPa}$ up to $3 \mathrm{MPa}$. The curve that shows the influence of $E$ on the variation of the constriction height has been plotted (fig. 15 (a)). As the Young modulus is increased, the walls are more rigid and less influenced by the fluid flow pressure, which results in a less important collapse. This is consistent with the findings of precedent numerical simulations (Payan et al., 2002). This is also in agreement with the fact that the compliance of the pharynx has always been pointed out as an important mechanical factor for the upper airway obstruction (Deegan and McNicholas, 1995). The impact of $E$ on the variation of the flow rate has also been studied (fig. 15 (b)). As $E$ increases, and as the walls tend to become more rigid, the value of the flow rate tends to an asymptotic value $\Phi_{\text {rigid }} \simeq 32.5$ $\mathrm{l} / \mathrm{min}$ that corresponds to the flow rate in a rigid channel of the same geometry. When $E$ decreases and is below the value of $\simeq 1 \mathrm{MPa}$, the flow rate $\Phi$ increases. This is a consequence of forcing $h_{c}^{\text {init }}$ to be constant for all the values of $E$. When $E$ is decreased, the height $h_{c}^{\text {rest }}$ corresponding to $P_{\text {ext }}=0$ has to be increased to keep the same $h_{c}^{\text {init }}$. This increases the area at the level of the constriction, and thus the flow rate.

Finally, the influence of the external pressure $P_{\text {ext }}$ has been investigated. This parameter is interesting as it modifies both the elasticity and the initial constriction height $h_{c}$ at the same time. In physiological reality, input parameters are indeed seldom independent. Moreover, this study allows to check if the model response to a complex input is correct. Simulations had been carried out, for a pressure drop $\Delta P$ of $150 \mathrm{~Pa}$, an initial constriction height $h_{c}^{\text {rest }}$ of $1.5 \mathrm{~mm}$ and a Young modulus $E$ of $1.6 \mathrm{MPa}$. The impact of varying the imposed external pressure on the constriction height variation is depicted in fig. 16 (a), with this time $\Delta h_{c}$ computed as following:

$$
\Delta h_{c}=\frac{h_{c}^{\mathrm{rest}}-h_{c}^{\mathrm{def}}}{h_{c}^{\mathrm{rest}}} .
$$

The curve shows a positive quasi-linear relationship between varying external pressure and resulting variation in constriction height. The influence of $P_{\text {ext }}$ on the flow rate is also depicted in fig. 16 (b). As $P_{\text {ext }}$ is increased, the duct at the level of the constriction becomes narrower. Thus, the flow rate is decreased, in a 
quasi-linear relationship with $P_{\text {ext }}$.

\section{Conclusion}

A numerical and experimental study of the fluid-structure interaction in the upper airway in conditions of expiratory flow and of major initial obstruction has been carried out. Under these particular conditions, simplificatory assumptions such as small deformations have been stated so as to simplify the governing equations of the interaction and to obtain a faster numerical solving. The resulting computation time of the order of ten minutes is of interest since it should be compatible with a use in a clinical context. A preliminary quantitative validation has been carried out based on a comparison between predictions from numerical simulations and measurements from an in-vitro set-up which reproduces in a simplified manner the geometry of the airway at the base of the tongue. Concerning the prediction of deformations, the average error is of order of $20 \%$, which is quite encouraging considering the amount of assumptions and indirect determinations that needed to be done.

At the level of the deformable tongue replica in the set-up, the duct is the narrowest. Basically, it creates strong pressure losses (Venturi effect) in the fluid. The resulting effect of the fluid-structure interaction is in this case a partial obstruction of the duct. Although the deformation of the artificial tongue is small, a clear phenomenon of flow limitation has been predicted. As the conditions in the set-up are close to those of the upper airway of snorers or apneic patients during sleep, this is in good agreement with the various phenomena of expiratory flow limitation reported in the literature. As a result, both the numerical simulations

and the set-up are suitable for further physical and physiological studies of the upper airway in conditions of expiration. It is noteworthy since expiratory abnormalities did not receive much attention in the literature while they are expected to be of great importance, for instance in the pathogenesis of obstructive sleep apnea (Woodson, 2003).

Of course, the ultimate goal of this research project, which is to build a complete validated numerical model of the pharyngeal upper airway, is far to be achieved. In particular, in the present state, the simulations are basically limited to expiratory effects and small deformations of the wall. While with the current theory, it is possible to carry out simulations of a complete airway collapse in inspiratory conditions and from geometries of real apneic patients (Chouly et al., 2006), further experimental work is needed to assess the validity of the model in this case. Moreover, a theoretical problem occurs with the description of the contact between the tongue and the pharyngeal walls as is expected during a complete obstruction. Different theoretical solutions based on Hertz models (Stronge, 2000) are currently investigated. Because of the strong nonlinearity induced, the collision model is expected to be of major importance for the validity of the simulations. Also, the assumption of the bidimensional closure of the airway should be investigated more carefully. Even though the backward motion of the tongue and of the soft-palate play a major role, there is observational evidence that the lateral walls are also involved in the collapse (Ayappa and Rapoport, 2003). If so, a full three-dimensional formulation should be developed and validated.

A similar effort concerning the experimental validation of the simulations must be developed in parallel. Experiments in conditions different from expiratory flow (inspiratory flow or complete respiratory cycle) and strong initial obstruction would allow us to study a wider range of anatomical and biomechanical properties, corresponding to different types of patients, of physiological conditions and of pathologies. For instance, a technique called NEP has been used to detect expiratory flow limitation (Verin et al., 2002). It consists in applying a negative pressure at the mouth during tidal expiration to detect flow limitation in spontaneous breathing (Boczkowski et al., 1997). It is clear that our study is not relevant for this technique since the pressure distribution in the airflow is globally positive or equal to 0 in the experiments carried out in-vitro. Moreover, extensive studies of airway pathologies such as obstructive apnea or snoring would presuppose other conditions. In particular, inspiratory flow would be requiered for sleep apnea. For snoring, the strong 
instationnary effects should be integrated in the numerical model (such as in (Balint and Lucey, 2005)) and measured in the in-vitro set-up. Also, we acknowledge that the current in-vitro set-up may be far away from the true geometry and mechanics of the upper airway. More realistic pharyngeal geometry need to be considered though the design, the realization and the control of complex geometries is quite challenging. Finally, measurements of two (or even three) dimensional deformations together with accurate fluid mechanical measurements should be requiered. A set-up involving a digital camera coupled with pressure and velocity sensors is currently developed for this purpose. It should enable measurements such as those obtained in (Elad et al., 1992) for the collapsible tube.

\section{Acknowledgements}

The authors would like to thank Alice Perret for her contribution, as well as Jacques Ohayon and Pascal Swider for their comments. They would like to thank also Jean-Roch Paoli for his help on clinical aspects. The work is part of an Emergence project granted by the CNRS federations ELESA/IMAG and the RhôneAlpes region, France.

\section{Appendix A. Precomputation method}

The aim is to obtain $[\mathbf{M}]$ and $\left\{\mathbf{u}_{\mathbf{f}}{ }^{*}\right\}$ that appear in the following relationship:

$$
\left\{\mathbf{u}_{\mathbf{f}}\right\}=[\mathbf{M}]\{\mathbf{F}\}+\left\{\mathbf{u}_{\mathbf{f}}^{*}\right\} .
$$

If it is not possible to obtain directly from the finite element solver the requiered matrices and vector, the following precomputation method can be applied, based on the fact that any solver will give the value of displacement $\left\{\mathbf{u}_{\mathbf{f}}\right\}$ for a given set of forces $\{\mathbf{F}\}$ :

(i) compute $\left\{\mathbf{u}_{\mathbf{f}}{ }^{*}\right\}$ by application of forces $\{\mathbf{F}\}=\{\mathbf{0}\}$. In the particular case of the latex cylinder, $\left\{\mathbf{u}_{\mathbf{f}}{ }^{*}\right\}$ is already known to be $\{\mathbf{0}\}$ since kinematic constraints are immobility constraints.

(ii) compute $[\mathbf{M}]$. Set $\{\mathbf{F}\}=\left\{\boldsymbol{\Pi}_{\boldsymbol{i}}\right\}$, for each component $i$ of $\{\mathbf{F}\}$, where

$$
\left\{\boldsymbol{\Pi}_{i}\right\}=\{0, \ldots, 0, \underbrace{1}_{i^{t h} \text { position }}, 0, \ldots, 0\}^{T},
$$

it is clear from (A.1) that the vector $\left\{\mathbf{u}_{\mathbf{f}}{ }^{\mathbf{i}}\right\}$ obtained is the $i^{\text {th }}$ column $\left\{\mathbf{M}^{\mathbf{i}}\right\}$ of $[\mathbf{M}]$.

(iii) build $[\mathbf{M}]$ from all the $\left\{\mathbf{M}^{\mathbf{i}}\right\}$ and store it.

\section{Appendix B. Computation of pressure forces on each element}

The aim is to demonstrate how formula (12) is obtained for a discrete pressure distribution on an element. First, from (10), the matrix $[\mathbf{N}(s)]$ for a linear four nodes element can be detailed:

$$
[\mathbf{N}(s)]=[\quad Q(s) \mathbf{I} \quad Q(-s) \mathbf{I}]
$$

with

$$
Q(s)=\frac{1}{2}(1+s)
$$


and $\mathbf{I}$ the identity matrix of dimension 2 (Ansys, 2002). Since the $\left\{\mathbf{F}_{\text {nodes }}^{(e)}\right\}$ is a column vector constituted from the $\left\{\mathbf{F}_{k}^{(e)}\right\}$ vectors, for $k \in\{-1,1\}$, it is straightforward from (B.1) and (10) that:

$$
\left\{\mathbf{F}_{k}^{(e)}\right\}=I_{k} \frac{\{\mathbf{a}\}}{2}
$$

with

$$
I_{k}=\int_{-1}^{1} Q(k s) p(s) d s .
$$

For a discrete pressure distribution $p\left[s_{i}\right]_{i=1, \ldots, n}$, with $p(s)$ constant on each rectangular element $(i)$ of coordinates $\left[s_{i}, s_{i+1}\right]$, the integral (B.4) can be rewritten:

$$
I_{k}=\sum_{i=1}^{n} p\left[s_{i}\right] \int_{s_{i}}^{s_{i+1}} Q(k s) d s .
$$

Thanks to formula (B.2) which explicits $Q$, this last integral can be expressed analytically:

$$
\int_{s_{i}}^{s_{i+1}} Q(k s) d s=\frac{1}{2} \int_{s_{i}}^{s_{i+1}}(1+k s) d s
$$

This last integral is easy to compute (area of trapezoid), so that:

$$
\int_{s_{i}}^{s_{i+1}} Q(k s) d s=\frac{k}{2} \omega\left(k s_{i}, k s_{i+1}\right),
$$

with $\omega(x, y)$ the function given in (13). Finally,

$$
I_{k}=\frac{k}{2} \sum_{i=1}^{n} p\left[s_{i}\right] \omega\left(k s_{i}, k s_{i+1}\right) .
$$

From (B.3) and (B.8), (12) is then obtained. In the case of a tridimensional element (hexaedra), the formula (12) can be extended easily as follows:

$$
\left\{\mathbf{F}_{l}^{k^{(e)}}\right\}=\left(k l \sum_{i=1}^{n} \sum_{j=1}^{m} p\left[s_{i}, t_{j}\right] \omega\left(k s_{i}, k s_{i+1}\right) \omega\left(l t_{j}, l t_{j+1}\right)\right) \frac{\{\mathbf{a}\}}{16},
$$

with $\left\{\mathbf{F}_{l}^{k^{(e)}}\right\}$ the force vector applied to the node of coordinates $(k, l) \in\{-1,1\}$ of the element, and $p\left[s_{i}, t_{j}\right]$ the discrete pressure distribution applied on the element surface delimited by the four nodes $(k, l)$. a is now obtained thanks to cross product of three of the nodes of the surface.

\section{References}

Aittokallio, M., Gyllenberg, M., Polo, O., 2001. A model of a snorer's upper airway. Mathematical Biosciences 170, 79-90.

Aittokallio, M., Polo, O., 2002. Adjustment of the human respiratory system to increased upper airway resistance during sleep: a model of a snorer's upper airway. Bulletin of Mathematical Biology 64, 3-28.

Allen, G., Shortall, B., Gemci, T., Corcoran, T., Chigier, N., 2004. Computational simulations of airflow in an in-vitro model of the pediatric upper airways. Transactions of the ASME 126, 604-613.

Ansys, 2002. Theory Reference. Release 6.1.

Auregan, Y., Depollier, C., 1995. Snoring: linear stability analysis and in-vitro experiments. Journal of Sound and Vibration 188, 39-54. 
Auregan, Y., Meslier, N., 1993. Modélisation des apnées obstructives du sommeil. Comptes-Rendus de l'Académie des Sciences (Série 2) 316, 1529-1534.

Ayappa, I., Rapoport, D., 2003. The upper airway in sleep: physiology of the pharynx. Sleep Medicine Reviews 7, 9-33.

Balint, T., Lucey, A., 2005. Instability of a cantilevered flexible plate in viscous channel flow. Journal of Fluids and Structures 20, 893-912.

Bellet, D., Barrau, J., 1990. Cours d'élasticité. Cépaduès Editions.

Berger, S., Jou, L.-D., 2000. Flows in stenotic vessels. Annual Review of Fluid Mechanics 32, 347-382.

Boczkowski, J., Murciano, D., Pichot, M.-H., Ferretti, A., Pariente, R., Milic-Emili, J., 1997. Expiratory flow limitation in stable asthmatic patients during resting breathing. American Journal of Respiratory and Critical Care Medicine 156, 752-757.

Bonet, J., Wood, R., 1997. Nonlinear continuum mechanics for finite element analysis. Cambridge University Press.

Cancelli, C., Pedley, T., 1985. A separated-flow model for collapsible-tube oscillations. Journal of Fluid Mechanics 157, 375-404.

Chouly, F., 2005. Modélisation physique des voies aériennes supérieures pour le syndrome d'apnées obstructives du sommeil. Ph.D. thesis, Institut National Polytechnique de Grenoble, France.

Chouly, F., Van Hirtum, A., Lagrée, P.-Y., Paoli, J.-R., Pelorson, X., Payan, Y., 2006. Simulation of the retroglossal fluid-structure interaction during obstructive sleep apnea. Lecture Notes in Computer Science LNCS 4072, 48-57.

Cotin, S., Delingette, H., Ayache, N., 1999. Real-time elastic deformations of soft tissues for surgery simulation. IEEE Transactions On Visualization And Computer Graphics 5, 62-73.

Cousteix, J., 1988. Couche Limite Laminaire. Cépaduès Editions.

Deegan, P., McNicholas, W., 1995. Pathophysiology of obstructive sleep apnoea. European Respiratory Journal 8, 1161-1178.

Elad, D., Sahar, M., Avidor, J., Einav, S., 1992. Steady flow through collapsible tubes: measurements of flow and geometry. Journal of Biomechanical Engineering 114, 84-91.

Flemons, W. W., 2002. Obstructive sleep apnea. The New England Journal Of Medicine 347, 498-504.

Fodil, R., Brugel-Ribere, L., Croce, C., Sbirlea-Apiou, G., Larger, C., Papon, J., Delclaux, C., Coste, A., Isabey, D., Louis, B., 2005. Inspiratory flow in the nose: a model coupling flow and vasoerectile tissue distensibility. Journal of Applied Physiology 98, 288-295.

Fodil, R., Ribreau, C., Louis, B., Lofaso, F., Isabey, D., 1997. Interaction between steady flow and individualised compliant segments: application to upper airways. Medical and Biological Engineering and Computing $35,1-11$.

Fogel, R., Malhotra, A., White, D., 2004. Sleep - 2: Pathophysiology of obstructive sleep apnoea/hypopnoea syndrome. Thorax 59, 159-163.

Gavriely, N., Jensen, O., 1993. Theory and measurements of snores. Journal of Applied Physiology 74 (6), $2828-2837$.

Hazel, A., Heil, M., 2003. Steady finite-Reynolds number flows in three-dimensional collapsible tubes. Journal of Fluid Mechanics 486, 79-103.

Heil, M., Pedley, T., 1996. Large post-buckling deformations of cylindrical shells conveying viscous flow. Journal of Fluids and Structures 10, 565-599.

Hofmans, G., Groot, G., Ranucci, M., Graziani, G., Hirschberg, A., 2003. Unsteady flow through in-vitro models of the glottis. Journal of the Acoustical Society of America 113, 1658-1675.

Huang, L., 1995. Mechanical modeling of palatal snoring. Journal of the Acoustical Society of America 97, $3642-3648$.

Huang, L., Ffowcs Williams, J.-E., 1999. Neuromechanical interaction in human snoring and upper airway obstruction. Journal of Applied Physiology 86, 1759-1763.

Huang, Y., Malhotra, A., White, D., 2005a. Computational simulation of human upper airway collapse using a pressure-/state-dependent model of genioglossal muscle contraction under laminar flow conditions. Journal of Applied Physiology 99, 1138-1148.

Huang, Y., White, D.-P., Malhotra, A., 2005b. The impact of anatomic manipulations on pharyngeal collapse 
- results from a computational model of the normal human upper airway. Chest 128, 1324-1330.

Imbert, J., 1991. Analyse des structures par éléments finis. Cépaduès Editions.

Isono, S., Remmers, J., Tanaka, A., Sho, Y., Sato, J., Nishino, T., 1997. Anatomy of pharynx in patients with obstructive sleep apnea and in normal subjects. Journal of Applied Physiology 82, 1319-1326.

Krieger, J., Petiau, C., Sforza, E., Weiss, T., Thibault, A., Bazin, A., 1998. Résisteur de Starling et stabilité du couple sommeil-ventilation. Neurophysiologie Clinique 28, 493-506.

Lagrée, P., Berger, E., Deverge, M., Vilain, C., Hirschberg, A., 2005. Characterization of the pressure drop in a 2D symmetrical pipe: some asymptotical, numerical and experimental comparisons. ZAMM - Journal of Applied Mathematics and Mechanics 85, 141-146.

Liu, Z., Luo, X., Lee, H., Lu, C., 2007. Snoring source identification and snoring noise prediction. Journal of Biomechanics (In Press).

Lofaso, F., Lorino, A., Fodil, R., Pia D’Ortho, M., Isabey, D., Lorino, H., Goldenberg, F., Harf, A., 1998. Heavy snoring with upper airway resistance syndrome may induce intrinsic positive end-expiratory pressure. Journal of Applied Physiology 85, 860-866.

Luo, X.-Y., Pedley, T.-J., 1995. A numerical simulation of steady flow in a 2-D collapsible channel. Journal of Fluids and Structures 9, 149-174.

Malhotra, A., Huang, Y., Fogel, R.-B., Pillar, G., Edwards, J.-K., Kikinis, R., Loring, S.-H., White, D.-P., 2002. The male predisposition to pharyngeal collapse. American Journal of Respiratory and Critical Care Medicine 166, 1388-1395.

Malhotra, A., White, D.-P., 2002. Obstructive sleep apnoea. The Lancet 360, 237-245.

Martin, R.-J., Pennock, B.-E., Orr, W.-C., Sanders, M.-H., Rogers, R.-M., 1980. Respiratory mechanics and timing during sleep in occlusive sleep apnea. Journal of Applied Physiology 48, 432-437.

Massiot, O., 2004. Modeling flow-induced collapse in human airways. Ph.D. thesis, Universiteit Twente, The Netherlands.

Payan, Y., Chabanas, M., Pelorson, X., Vilain, C., Levy, P., Luboz, V., Perrier, P., 2002. Biomechanical models to simulate consequences of maxillofacial surgery. Comptes-Rendus de l'Académie des Sciences (Série Biologies) 325, 407-417.

Pelorson, X., Hirschberg, A., Wijnands, A.-P.-J., Bailliet, H., 1995. Description of the flow through in-vitro models of the glottis during phonation. Acta Acustica 3, 191-202.

Remmers, J.-E., De Groot, W.-J., Sauerland, E.-K., Anch, A.-M., 1978. Pathogenesis of upper airway occlusion during sleep. Journal of Applied Physiology 44, 931-938.

Sanders, D., Moore, S., 1983. Inspiratory and expiratory partitioning of airway resistance during sleep in patients with sleep apnea. American Review of Respiratory Diseases 127, 554-558.

Scherer, R.-C., Shinwari, D., De Witt, K.-J., Zhang, C., Kucinschi, B.-R., Afjeh, A.-A., 2001. Intraglottal pressure profiles for a symmetric and oblique glottis with a divergence angle of 10 degrees. Journal of the Acoustical Society of America 109, 1616-1630.

Scherer, R.-C., Titze, I.-R., 1983. Vocal fold physiology: contemporary research and clinical issues. D.M. Bless and J.H. Abbs (College Hill, San Diego), Ch. 'Pressure-flow relationship in a model of the laryngeal airway with diverging glottis', pp. 177-193.

Schlichting, H., 1979. Boundary-layer theory. McGraw-Hill Publishing Company.

Schwab, R.-J., Pasirstein, M., Pierson, R., Mackley, A., Hachadoorian, R., Arens, R., Maislin, G., Pack, A.I., 2003. Identification of upper airway anatomic risk factors for obstructive sleep apnea with volumetric magnetic resonance imaging. American Journal of Respiratory and Critical Care Medicine 168, 522-530.

Sforza, E., Bacon, W., Weiss, T., Thibault, A., Petiau, C., Krieger, J., 2000. Upper airway collapsibility and cephalometric variables in patients with obstructive sleep apnea. American Journal of Respiratory and Critical Care Medicine 161, 347-352.

Shapiro, A.-H., 1977. Steady flow in collapsible tubes. Journal of Biomechanical Engineering 99, $126-147$.

Shome, B., Wang, L.-P., Santare, M.-H., Prasad, A.-K., Szeri, A.-Z., Roberts, D., 1998. Modeling of airflow in the pharynx with application to sleep apnea. Journal of Biomechanical Engineering 120, 416-422.

Smith, P.-L., Wise, R.-A., Gold, A.-R., Schwartz, A.-R., Permutt, S., 1988. Upper airway pressure-flow relationships in obstructive sleep apnea. Journal of Applied Physiology 64, 789-795.

Stronge, W.-J., 2000. Impact mechanics. Cambridge University Press, London, UK. 
Stănescu, D., Kostianev, S., Sanna, A., Liistro, G., Veriter, C., 1996. Expiratory flow limitation during sleep in heavy snorers. European Respiratory Journal 9, 2116-2121.

Sung, S.-J., Jeong, S.-J., Yu, Y.-S., Hwang, C.-J., Pae, E.-K., 2006. Customized three-dimensional computational fluid dynamics simulation of the upper airway of obstructive sleep apnea. Angle Orthodontist 76, 5. Treloard, L.-R.-G., 1975. The physics of rubber elasticity (3rd edition). Oxford - Clarendon.

Van Hirtum, A., Pelorson, X., Lagrée, P.-Y., 2005. In vitro validation of some flow assumptions for the prediction of the pressure distribution during obstructive sleep apnoea. Medical and Biological Engineering and Computing 43, 162-171.

Verin, E., Tardif, C., Portier, F., Similowski, T., Pasquis, P., Muir, J.-F., 2002. Evidence for expiratory flow limitation of extrathoracic origin in patients with obstructive sleep apnoea. Thorax 57, 423-428.

Walsh, R.-E., Michaelson, E.-D., Harkleroad, L.-E., Zighelboim, A., Sackner, M.-A., 1972. Upper airway obstruction in obese patients with sleep disturbance and somnolence. Annals of Internal Medicine 76, 185192.

Woodson, B., 2003. Expiratory pharyngeal airway obstruction during sleep: a multiple element model. Laryngoscope 113, 1450-1459.

$\mathrm{Xu}, \mathrm{C}$., 2005. Computational mechanics models for studying the pathogenesis of obstructive sleep apnea (OSA). Ph.D. thesis, Drexel University, United States.

Xu, C., Sin, S., McDonough, J.-M., Udupa, J.-K., Guez, A., Arens, R., Wootton, D.-M., 2006. Computational fluid dynamics modeling of the upper airway of children with obstructive sleep apnea syndrome in steady flow. Journal of Biomechanics 39, 2043-2054.

Young, T., Palta, M., Dempsey, J., Skatrud, J., Weber, S., Badr, S., 1993. The occurence of sleep-disordered breathing among middle-aged adults. The New England Journal of Medicine 328, 1230-1235.

Zienkiewicz, O.-C., Taylor, R.-L., 1989. The finite element method. Basic formulation and linear problems. McGraw-Hill Book Company. 


\section{List of Figures}

1 Sagittal view of the upper airway. Most of apneic episodes occur within the pharynx, due to the deformation of soft tissue (tongue, soft palate).

2 Flow inside a constriction.

3 (a) Pressure and equivalent nodal forces on an element $(e) \cdot\left\{\mathbf{F}_{\text {nodes }}^{(e)}\right\}$ is constituted of $\mathbf{F}_{\text {node 1 }}^{(e)}$, $\mathbf{F}_{\text {node 2 }}^{(e)}$. (b) Coordinate system associated with an element $(e)$.

4 The general algorithm used for coupling fluid and structure. filled with water. The "airway" is the metallic pipe.

6 Sagittal view of the upper airway.

7 (a) Finite element model of the in-vitro set-up latex tube. (b) Boundary conditions associated to the latex tube. Nodes constrained to zero displacement are in blue. They are localized in the region of contact with the rigid pipe

8 Variations of the constriction height $h_{c}$ in response to the variations of the external pressure $P_{\text {ext }}$. Values for the normalization coefficients : $h_{c}^{0}=1.6 \mathrm{~mm}, P_{\mathrm{ext}}^{0}=1000 \mathrm{~Pa}$.

$9 \quad$ Simulation of a fluid-structure interaction, for $\Delta P=200 \mathrm{~Pa}, P_{\text {ext }}=200 \mathrm{~Pa}$ and $h_{c}=1.2$ mm. $R e \simeq 1154$. (a) Velocity profile. Note the acceleration of the fluid while entering the constriction. Flow separation and jet formation are observed. (b) Pressure distribution. Note the negative pressure at the location of the constriction.

10 Simulation of a fluid-structure interaction, for $\Delta P=200 \mathrm{~Pa}, P_{\text {ext }}=200 \mathrm{~Pa}$ and $h_{c}=1.2 \mathrm{~mm}$. (a) Lateral view of the latex tube, in initial position (dashed line) and after computation of the deformation (solid line). (b) Constriction height variation in response to inlet pressure. Comparison of theoretical and experimental values. (c) Evolution of the convergence criterion $c v$ with the iterations for each step.

11 Simulation of a fluid-structure interaction, for $\Delta P=290 \mathrm{~Pa}, P_{\text {ext }}=400 \mathrm{~Pa}$ and $h_{c}=0.87$ mm. $R e \simeq 971$. (a) Velocity profile. (b) Pressure distribution.

12 Simulation of a fluid-structure interaction, for $\Delta P=290 \mathrm{~Pa}, P_{\mathrm{ext}}=400 \mathrm{~Pa}$ and $h_{c}=0.87$ $\mathrm{mm}$. (a) Lateral view of the latex tube, in initial position (dashed line) and after computation of the deformation (solid line). (b) Constriction height variation in response to inlet pressure. Comparison of theoretical and experimental values. (c) Evolution of the convergence criterion $c v$ with the iterations for each step.

13 Flow rate $\Phi$ as a function of pressure drop $\Delta P$ for the simulations no. 1 (a) and no. 2 (b). The plain lines correspond to simulations with a deformable wall whereas the dashed lines correspond to simulations with a rigid wall.

14 Influence of the initial constriction height $h_{c}$ on the partial closure of the channel (a) and on the flow rate (b). Simulations with parameters : $\Delta P=150 \mathrm{~Pa}, P_{\text {ext }}=200 \mathrm{~Pa}, E=1.6 \mathrm{MPa}$.

15 Influence of the Young modulus $E$ on the partial closure of the channel (a) and on the flow rate (b). Simulations with parameters : $\Delta P=150 \mathrm{~Pa}, P_{\text {ext }}=200 \mathrm{~Pa}, h_{c}=1.5 \mathrm{~mm}$.

Influence of the external pressure $P_{\text {ext }}$ on the partial closure of the channel (a) and on the flow rate (b). Simulations with parameters : $\Delta P=150 \mathrm{~Pa}, h_{c}=1.5 \mathrm{~mm}, E=1.6 \mathrm{MPa}$. 


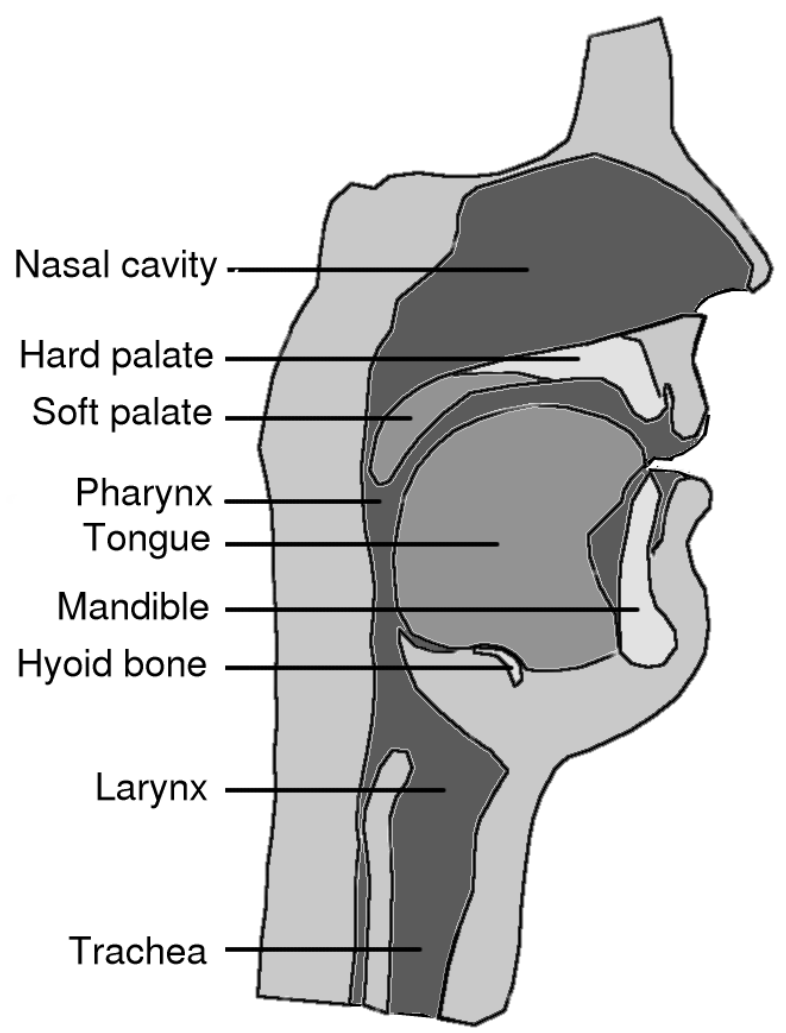

Fig. 1. Sagittal view of the upper airway. Most of apneic episodes occur within the pharynx, due to the deformation of soft tissue (tongue, soft palate).
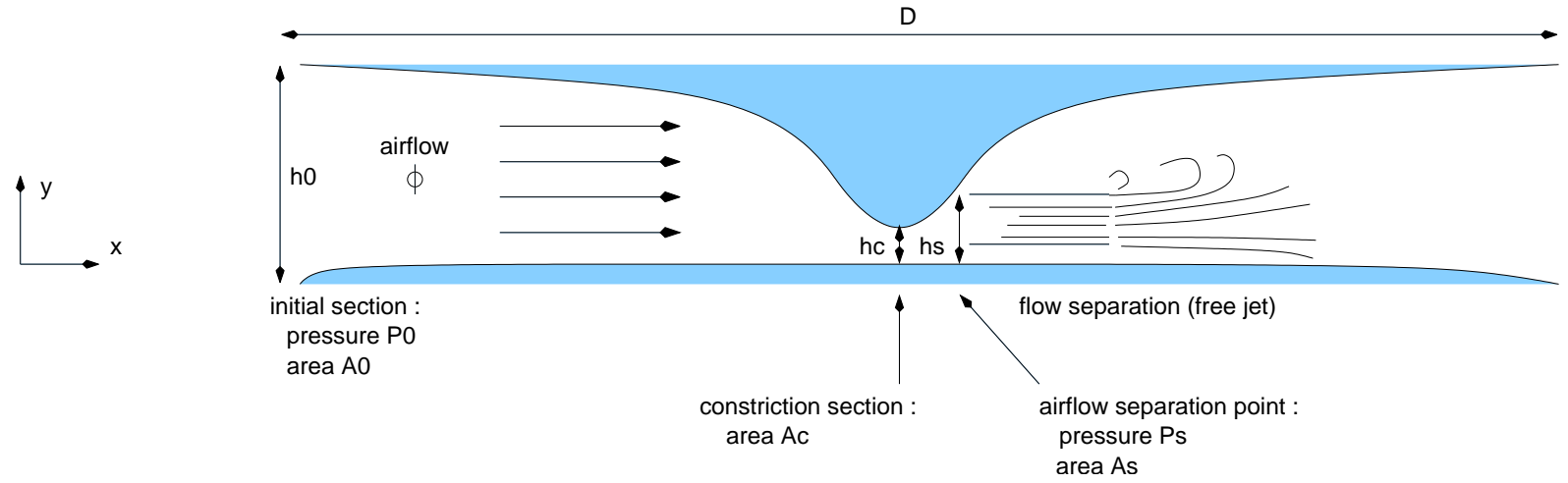

Fig. 2. Flow inside a constriction. 


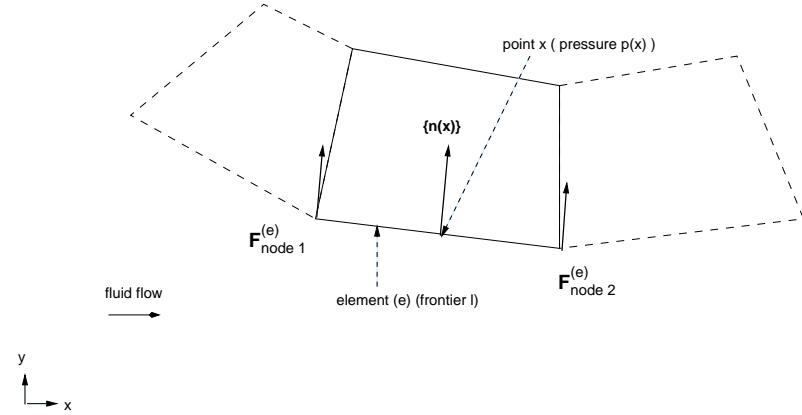

(a)

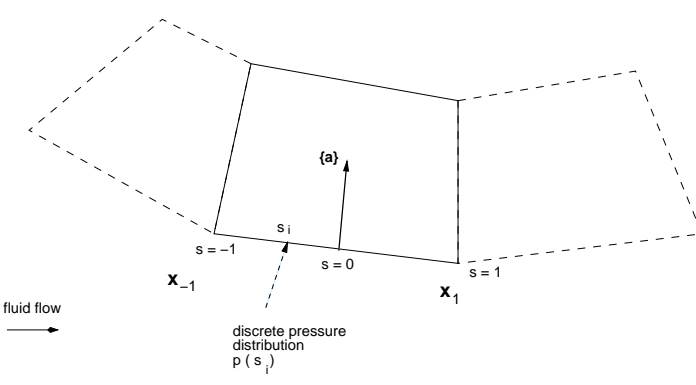

(b)

Fig. 3. (a) Pressure and equivalent nodal forces on an element $(e) \cdot\left\{\mathbf{F}_{\text {nodes }}^{(e)}\right\}$ is constituted of $\mathbf{F}_{\text {node 1 }}^{(e)}, \mathbf{F}_{\text {node 2 }}^{(e)}$ (b) Coordinate system associated with an element $(e)$.

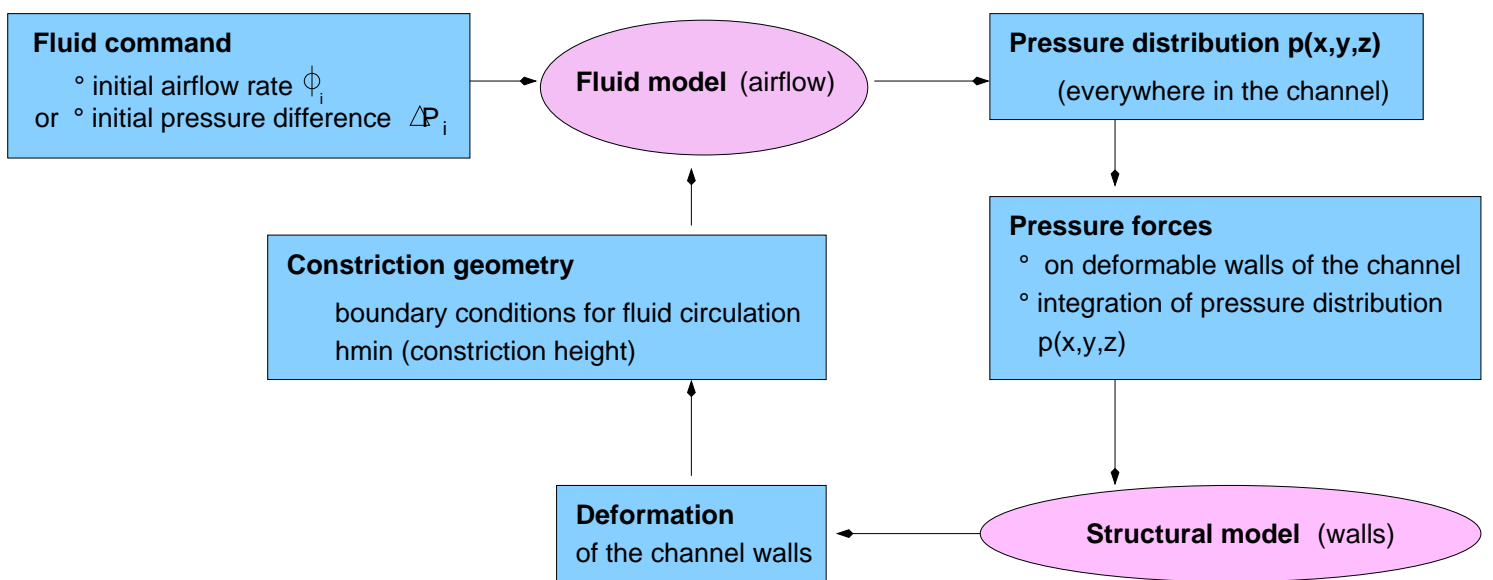

Fig. 4. The general algorithm used for coupling fluid and structure. 


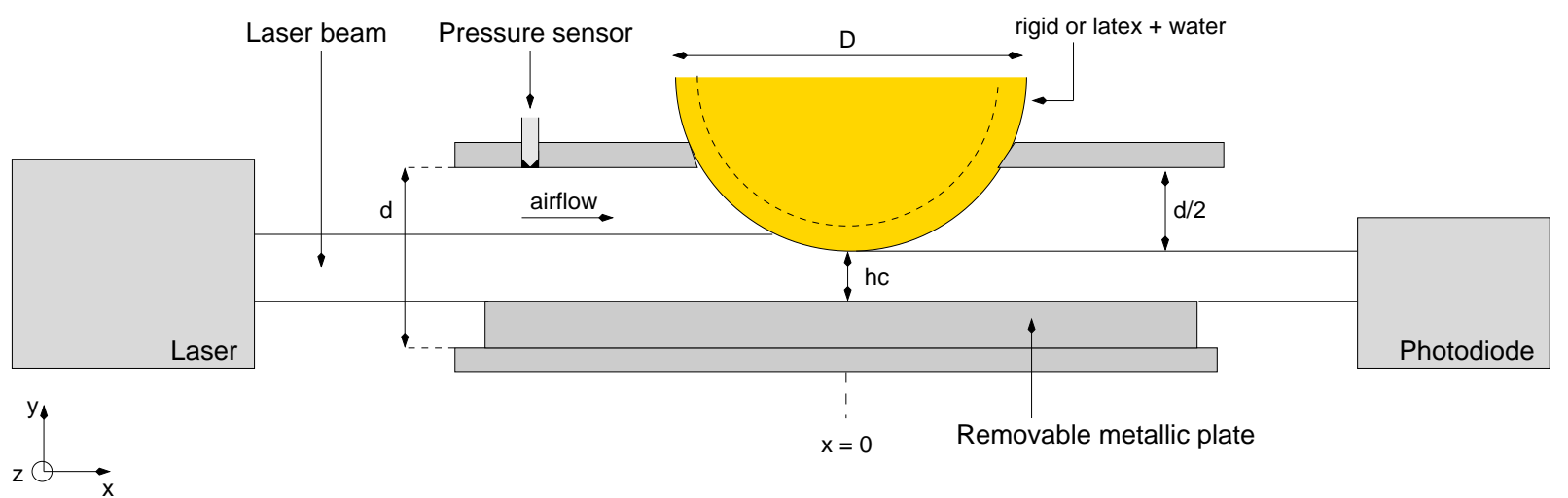

(a)

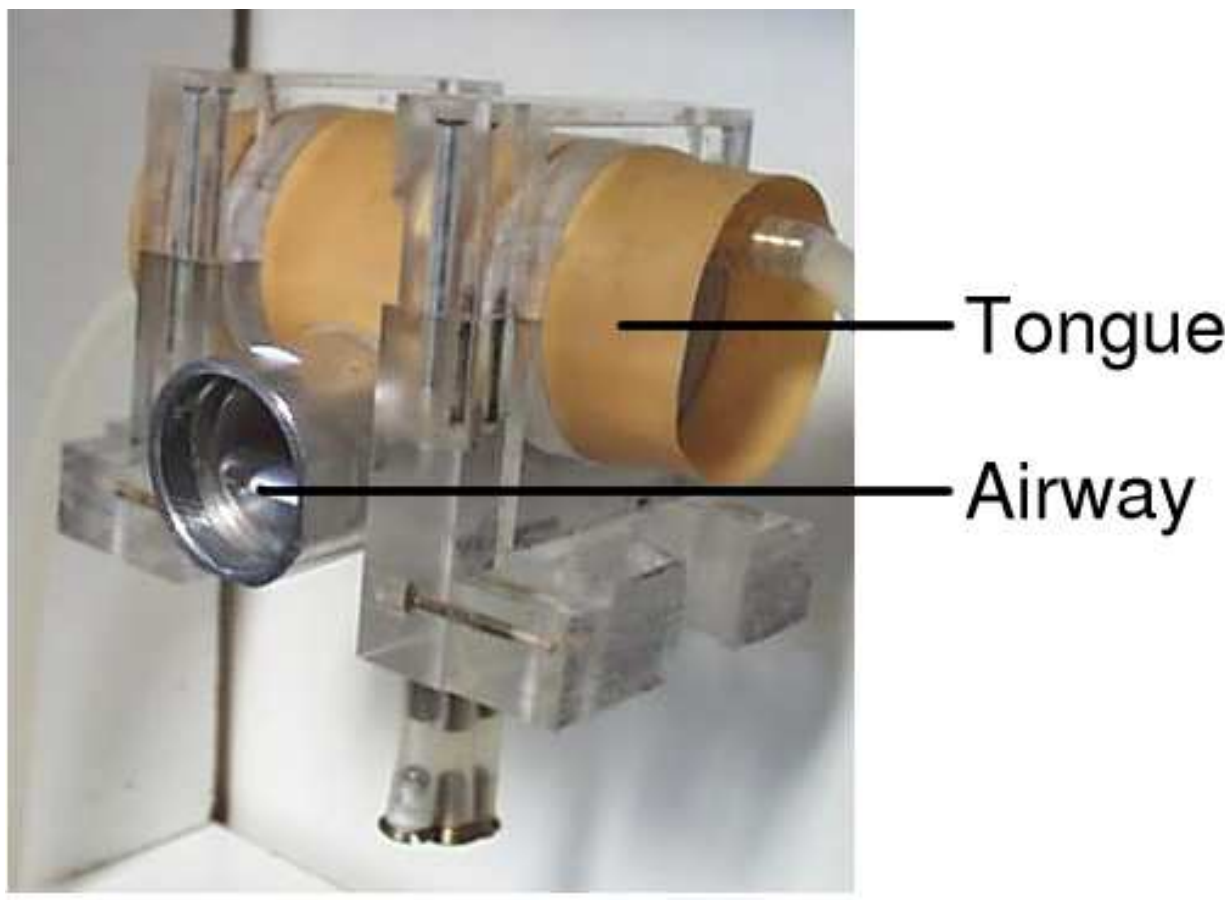

(b)

Fig. 5. (a) Schematic and (b) photography of the in-vitro set-up. The "tongue" is the latex tube filled with water. The "airway" is the metallic pipe. 


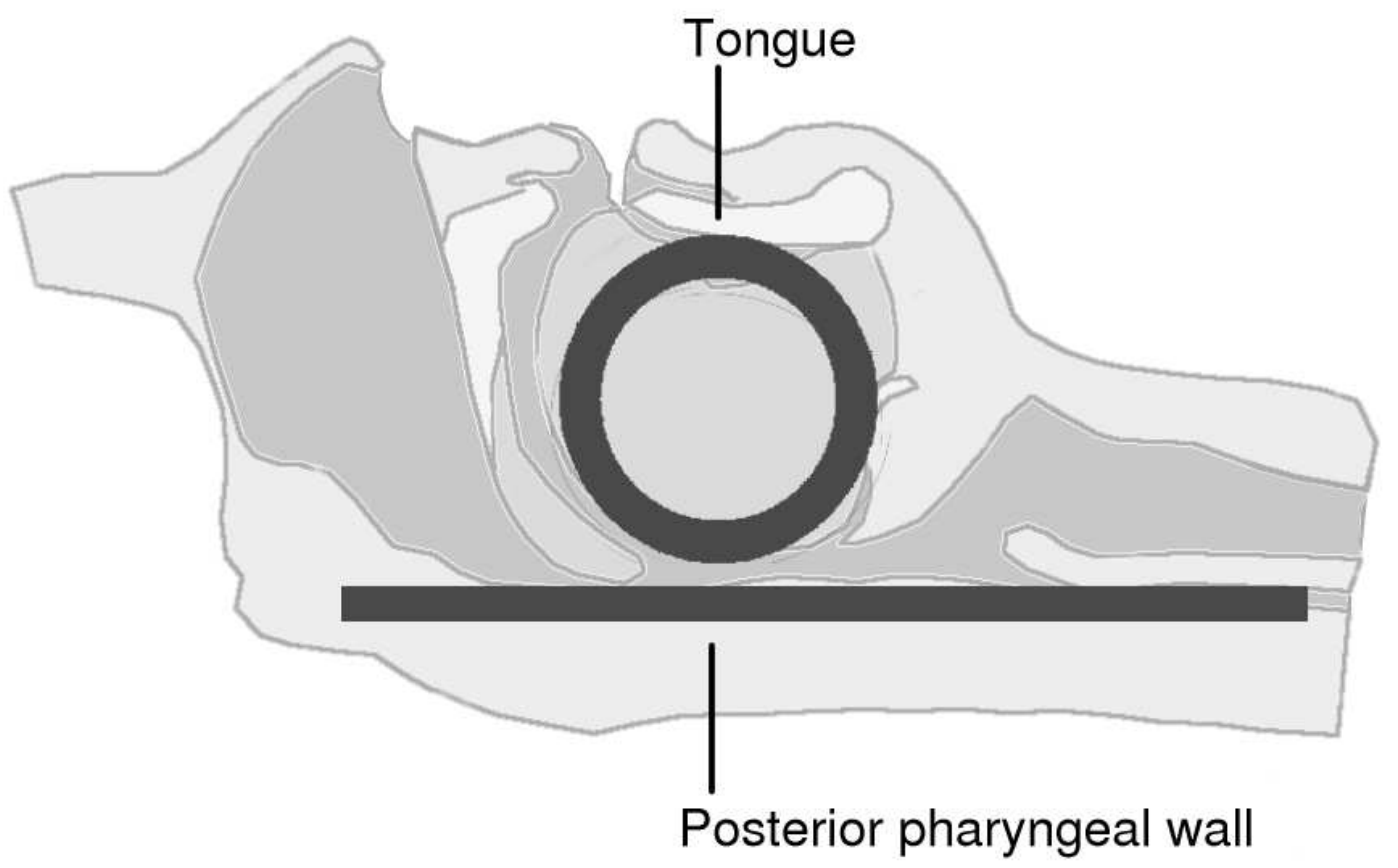

(c)

Fig. 6. Sagittal view of the upper airway.

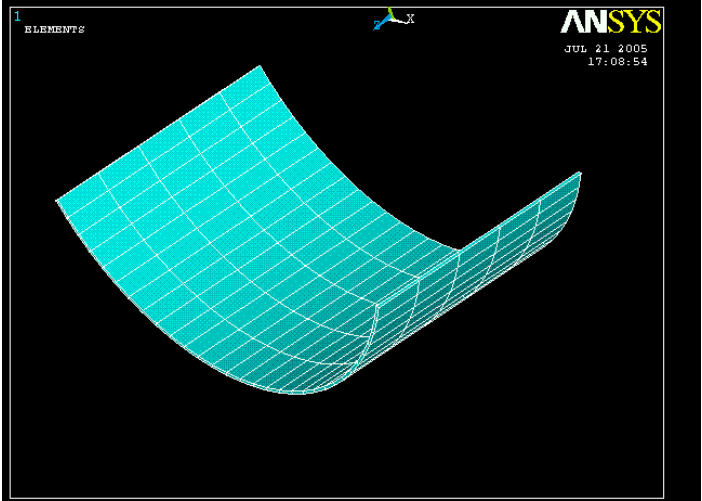

(a)

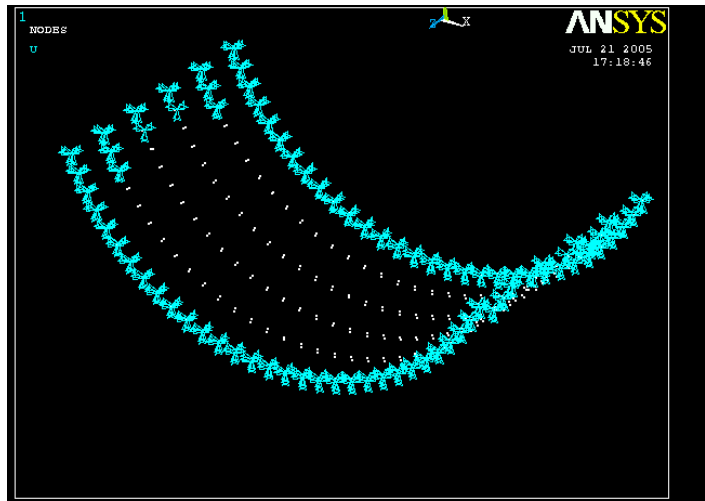

(b)

Fig. 7. (a) Finite element model of the in-vitro set-up latex tube. (b) Boundary conditions associated to the latex tube. Nodes constrained to zero displacement are in blue. They are localized in the region of contact with the rigid pipe 


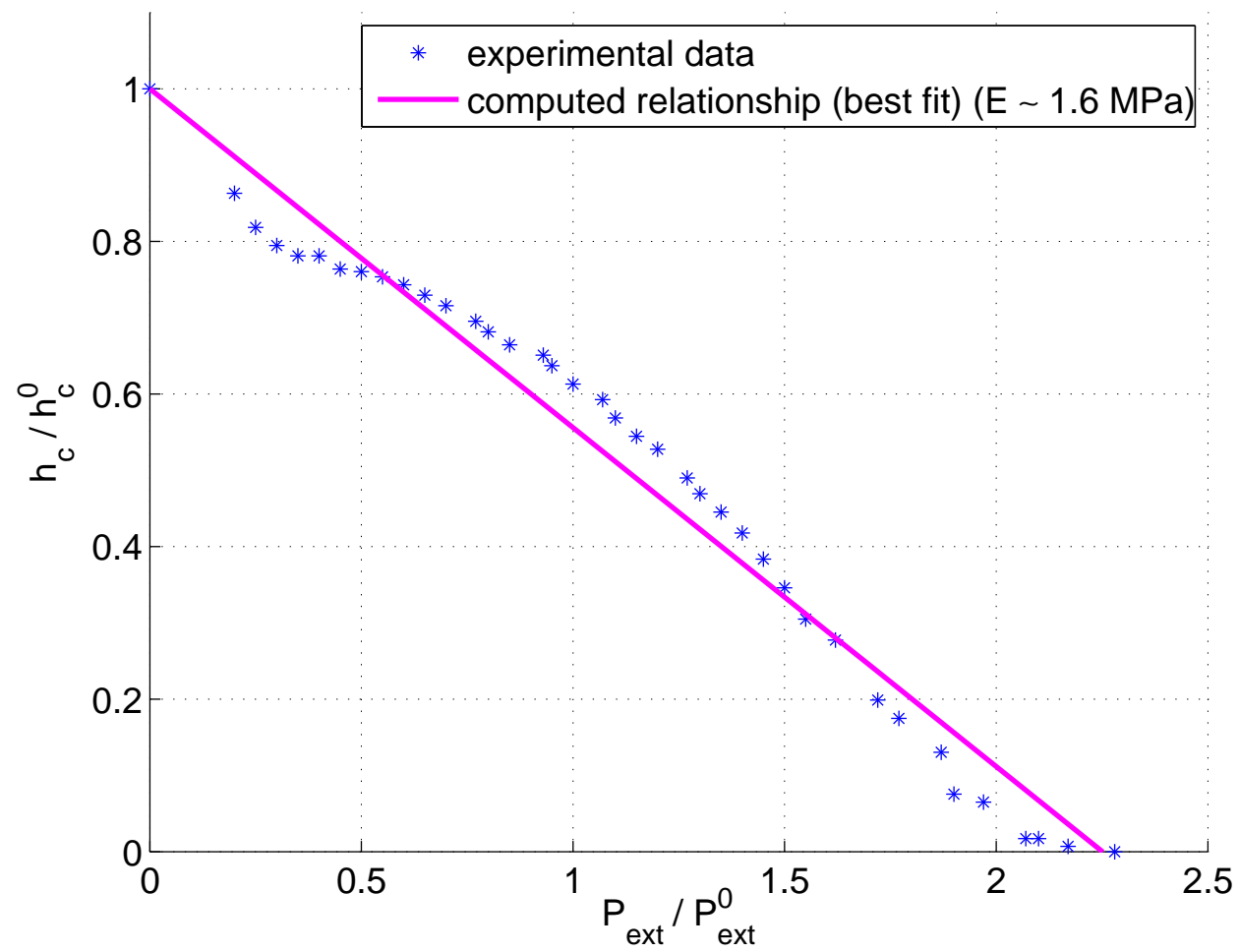

Fig. 8. Variations of the constriction height $h_{c}$ in response to the variations of the external pressure $P_{\text {ext }}$. Values for the normalization coefficients : $h_{c}^{0}=1.6 \mathrm{~mm}, P_{\mathrm{ext}}^{0}=1000 \mathrm{~Pa}$. 


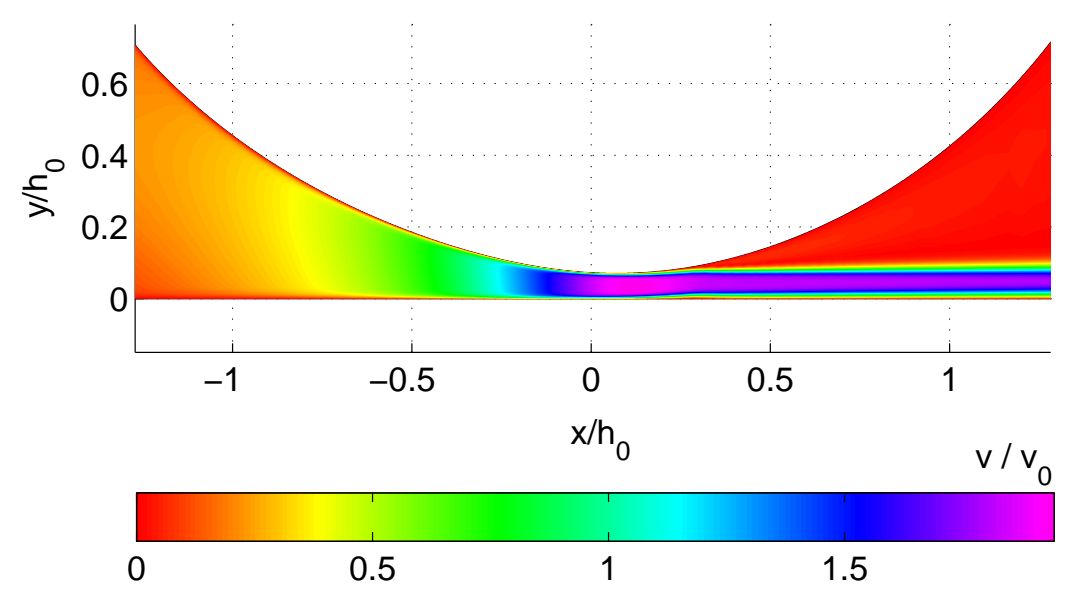

(a)

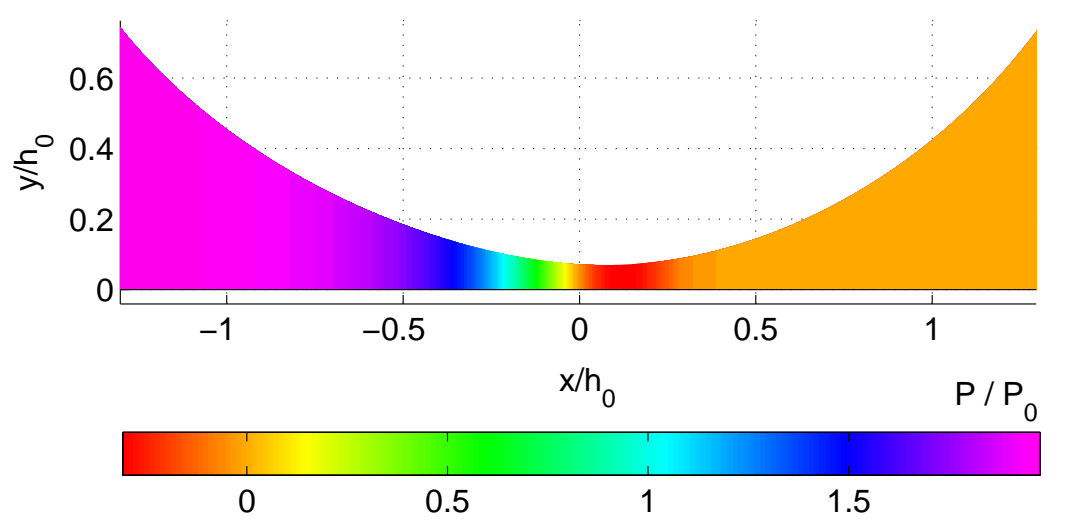

(b)

Fig. 9. Simulation of a fluid-structure interaction, for $\Delta P=200 \mathrm{~Pa}, P_{\text {ext }}=200 \mathrm{~Pa}$ and $h_{c}=1.2 \mathrm{~mm}$. Re $\simeq 1154$. (a) Velocity profile. Note the acceleration of the fluid while entering the constriction. Flow separation and jet formation are observed. (b) Pressure distribution. Note the negative pressure at the location of the constriction. 


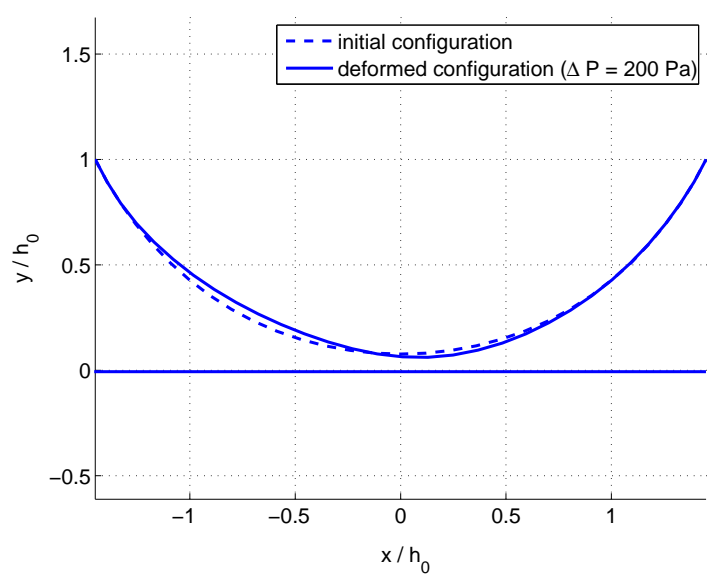

(a)

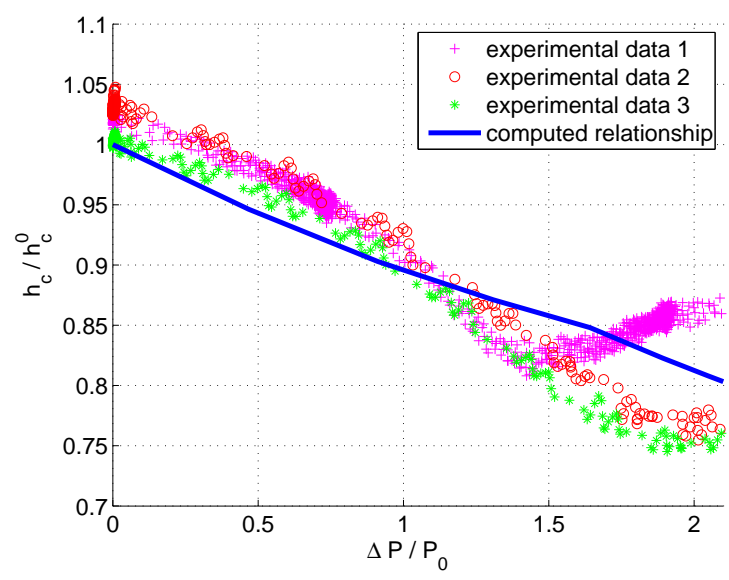

(b)

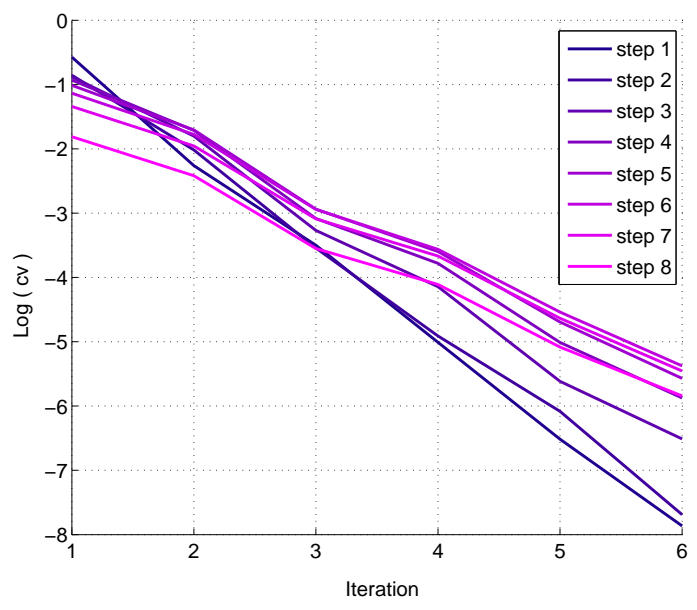

(c)

Fig. 10. Simulation of a fluid-structure interaction, for $\Delta P=200 \mathrm{~Pa}, P_{\text {ext }}=200 \mathrm{~Pa}$ and $h_{c}=1.2 \mathrm{~mm}$. (a) Lateral view of the latex tube, in initial position (dashed line) and after computation of the deformation (solid line). (b) Constriction height variation in response to inlet pressure. Comparison of theoretical and experimental values. (c) Evolution of the convergence criterion $c v$ with the iterations for each step. 


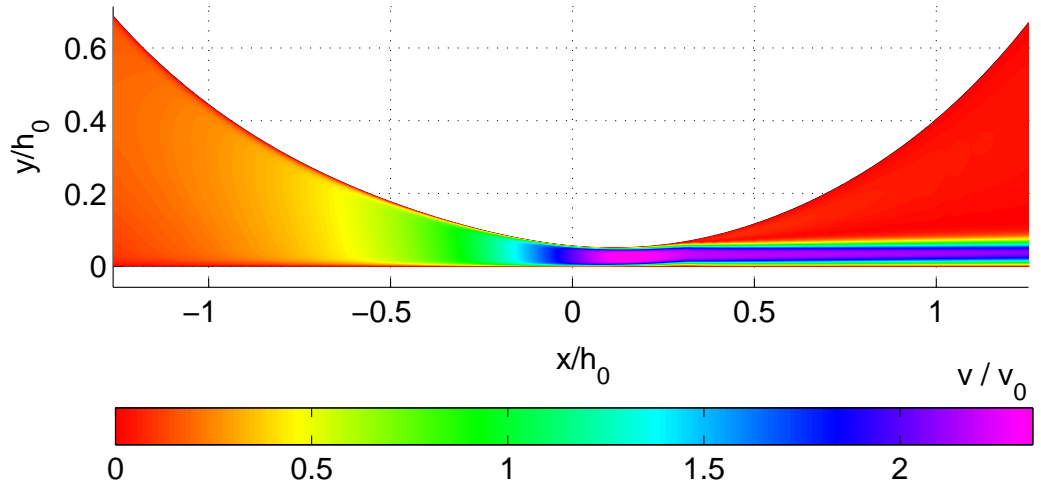

(a)

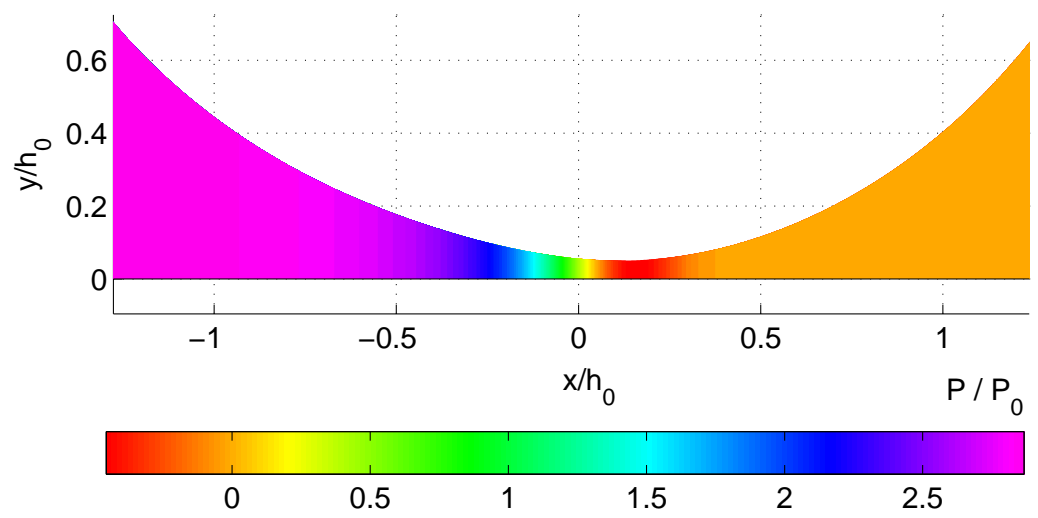

(b)

Fig. 11. Simulation of a fluid-structure interaction, for $\Delta P=290 \mathrm{~Pa}, P_{\text {ext }}=400 \mathrm{~Pa}$ and $h_{c}=0.87 \mathrm{~mm}$. Re $\simeq 971$. (a) Velocity profile. (b) Pressure distribution. 


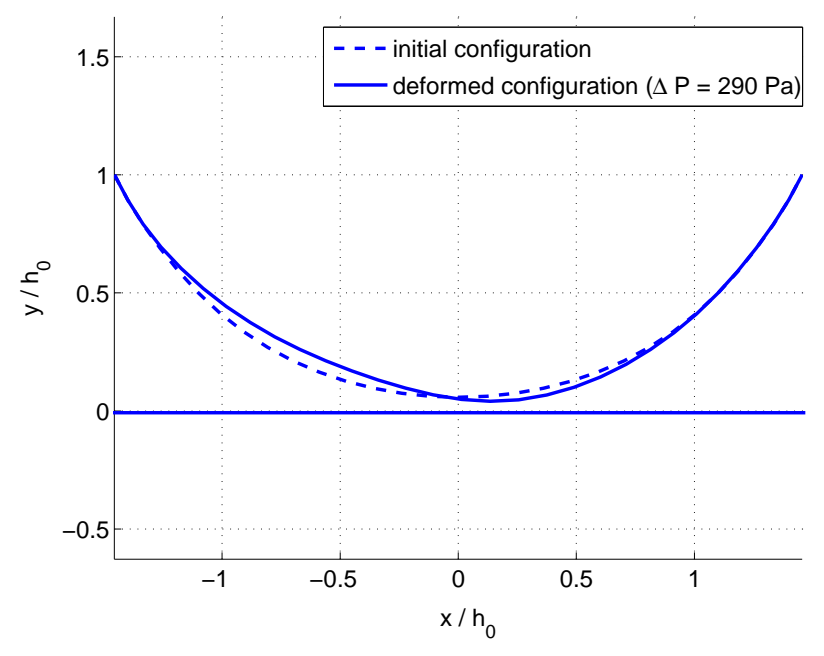

(a)
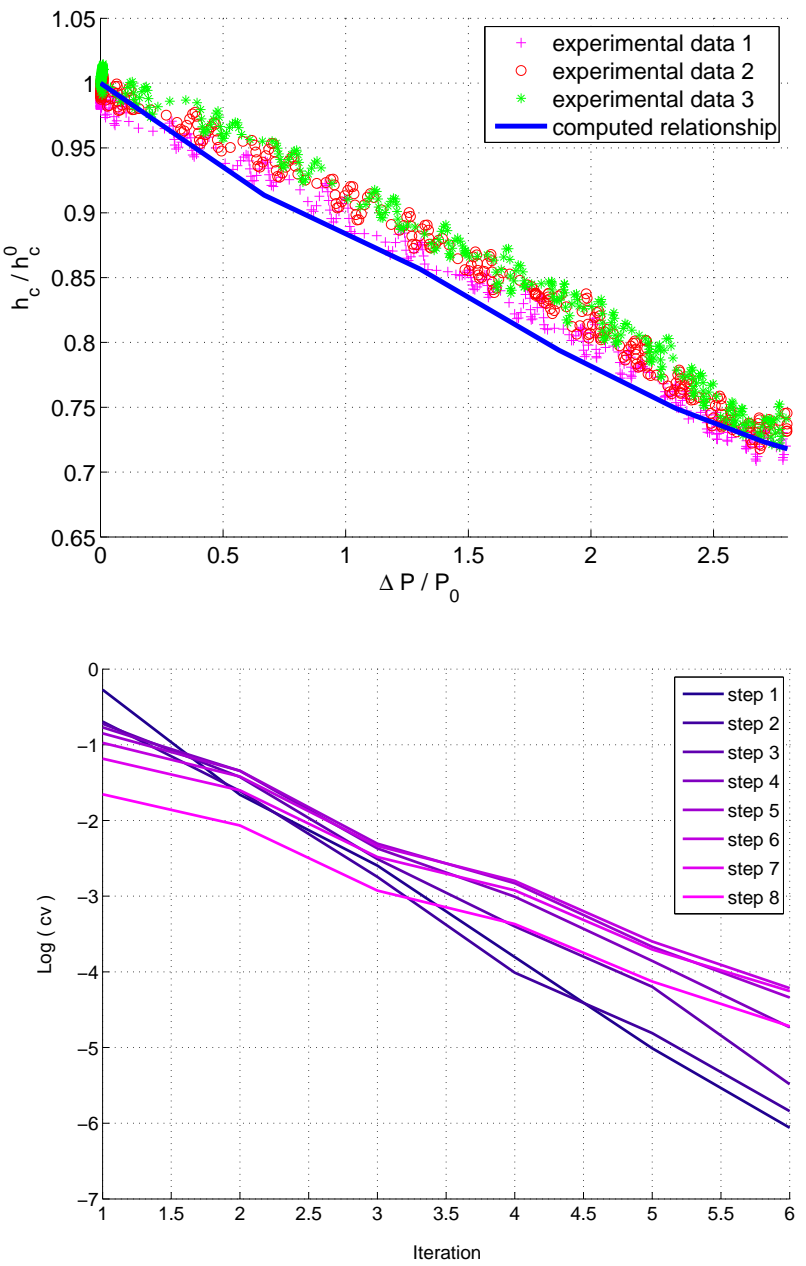

(c)

Fig. 12. Simulation of a fluid-structure interaction, for $\Delta P=290 \mathrm{~Pa}, P_{\text {ext }}=400 \mathrm{~Pa}$ and $h_{c}=0.87 \mathrm{~mm}$. (a) Lateral view of the latex tube, in initial position (dashed line) and after computation of the deformation (solid line). (b) Constriction height variation in response to inlet pressure. Comparison of theoretical and experimental values. (c) Evolution of the convergence criterion $c v$ with the iterations for each step. 


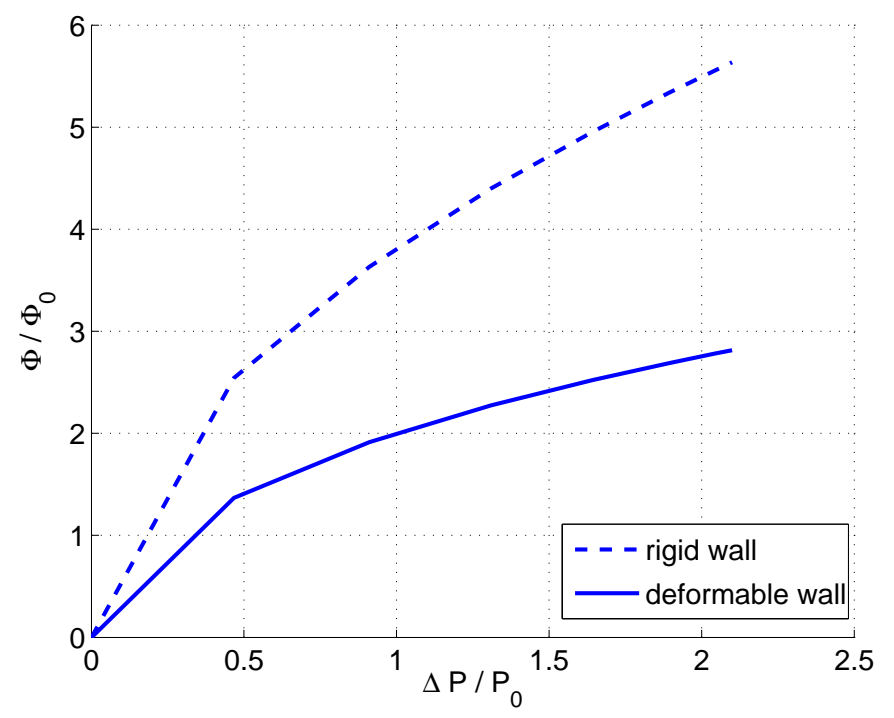

(a)

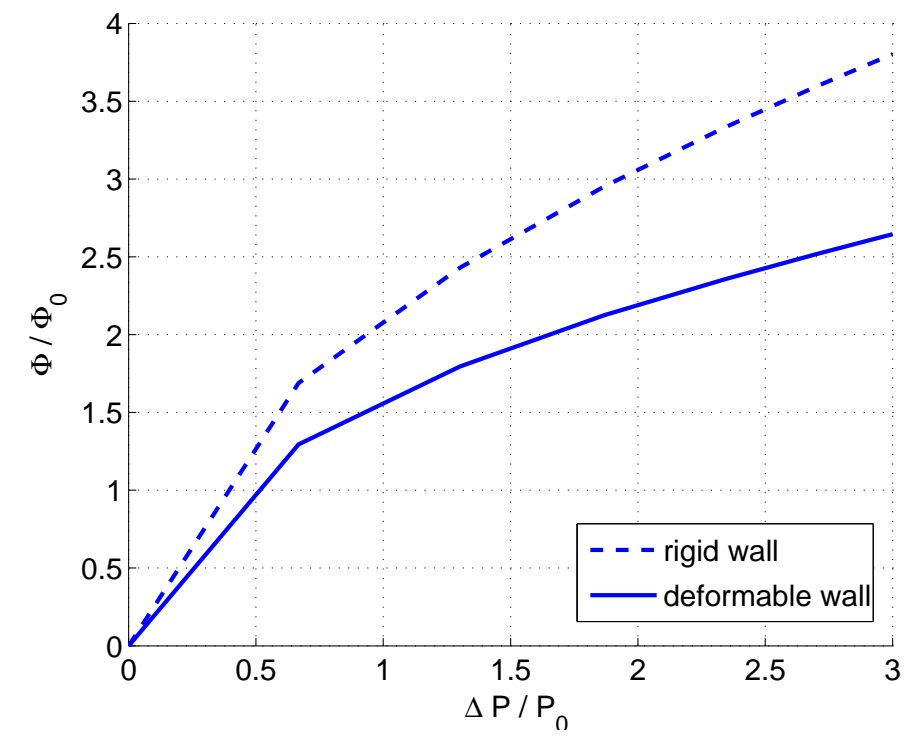

(b)

Fig. 13. Flow rate $\Phi$ as a function of pressure drop $\Delta P$ for the simulations no. 1 (a) and no. 2 (b). The plain lines correspond to simulations with a deformable wall whereas the dashed lines correspond to simulations with a rigid wall. 


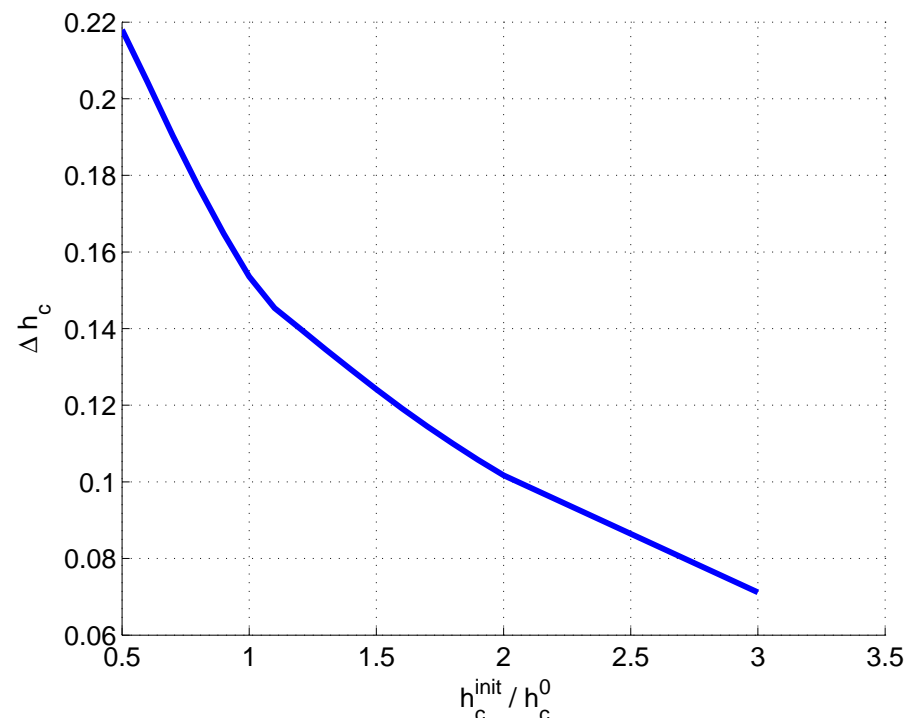

(a)

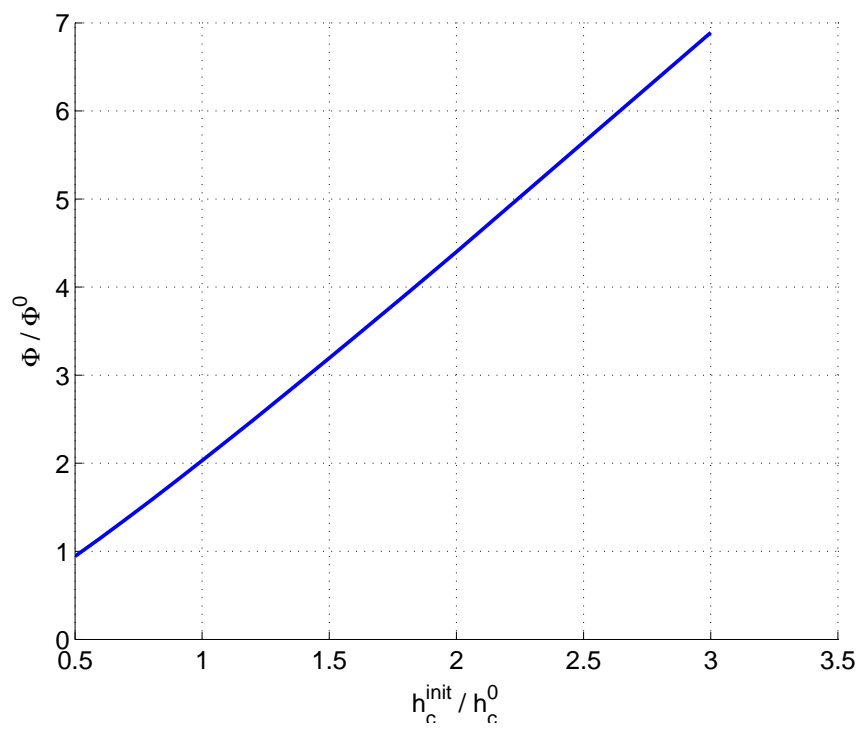

Fig. 14. Influence of the initial constriction height $h_{c}$ on the partial closure of the channel (a) and on the flow rate (b). Simulations with parameters : $\Delta P=150 \mathrm{~Pa}, P_{\text {ext }}=200 \mathrm{~Pa}, E=1.6 \mathrm{MPa}$. 


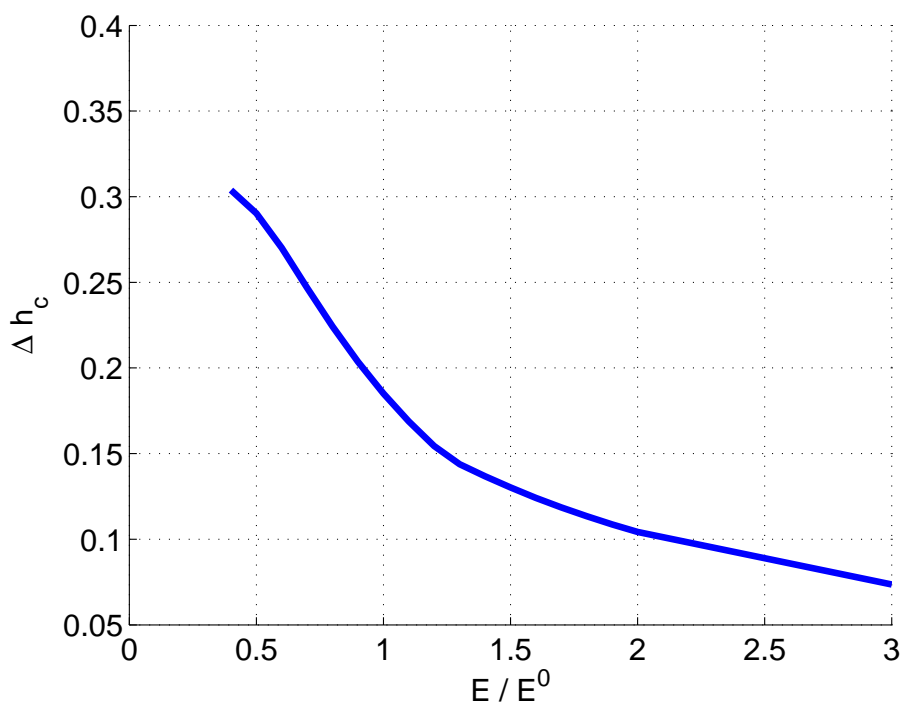

(a)

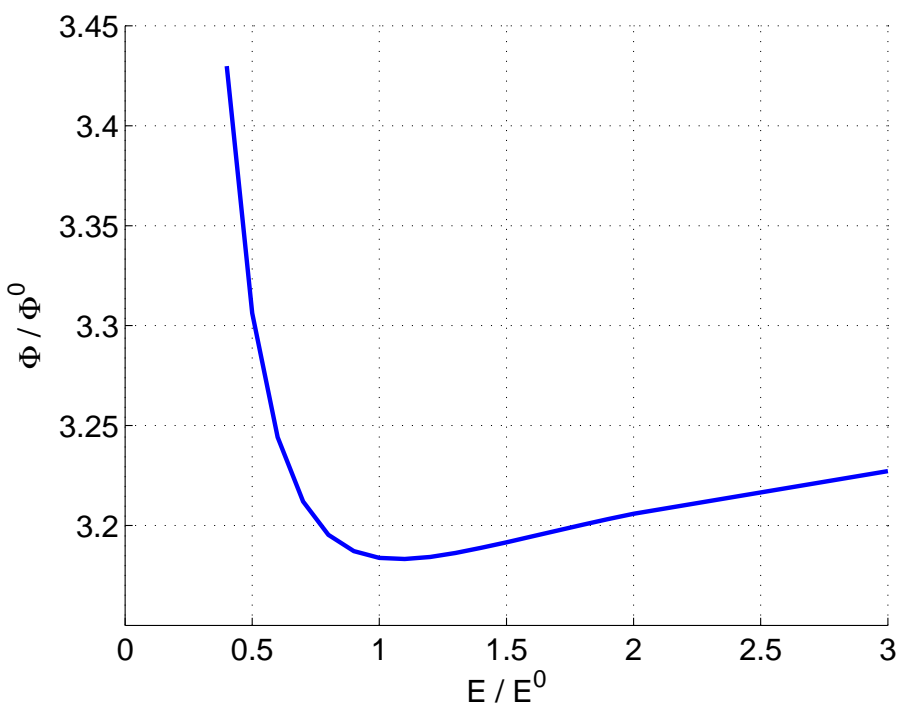

Fig. 15. Influence of the Young modulus $E$ on the partial closure of the channel (a) and on the flow rate (b). Simulations with parameters : $\Delta P=150 \mathrm{~Pa}, P_{\text {ext }}=200 \mathrm{~Pa}, h_{c}=1.5 \mathrm{~mm}$. 

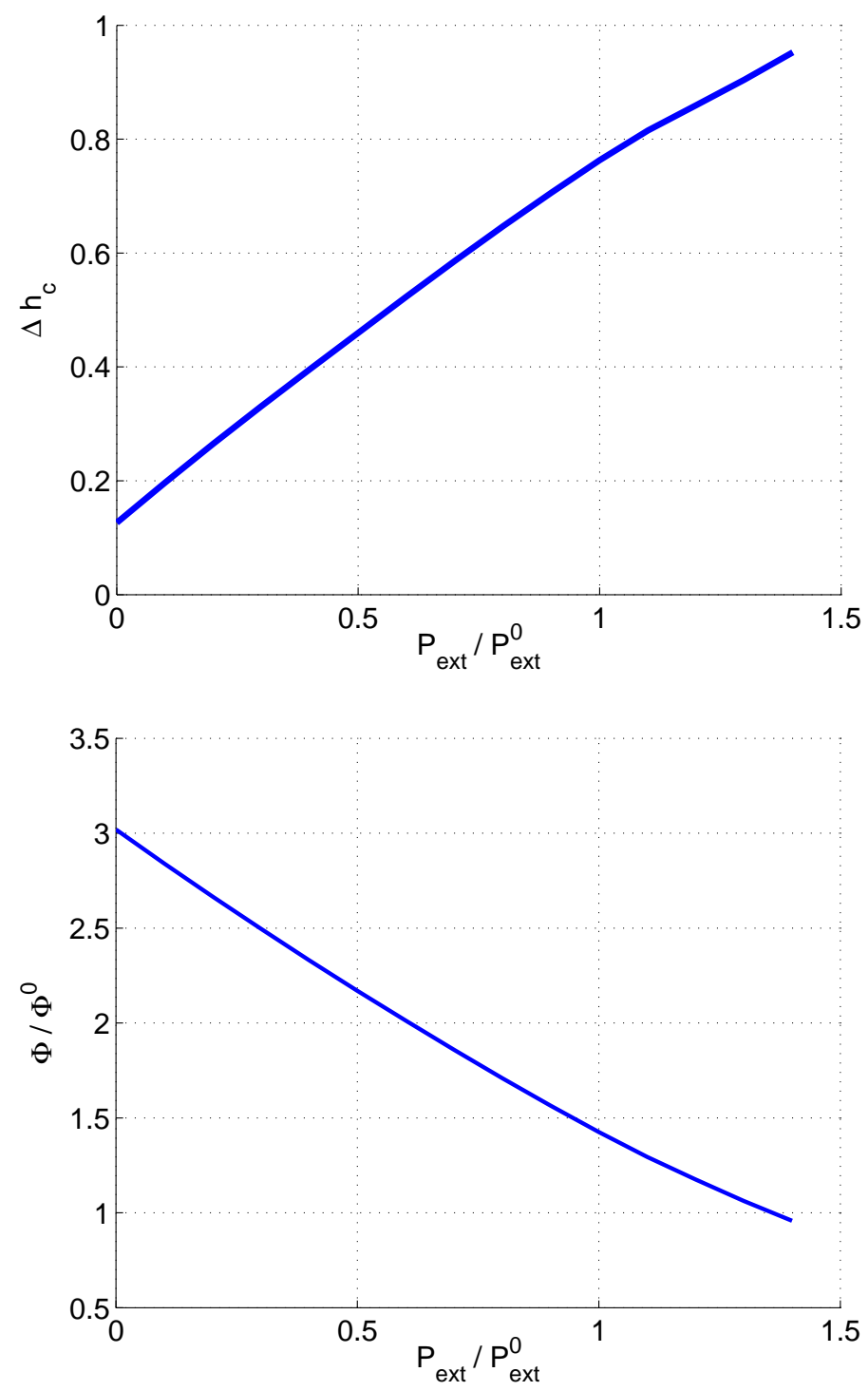

Fig. 16. Influence of the external pressure $P_{\text {ext }}$ on the partial closure of the channel (a) and on the flow rate (b). Simulations with parameters : $\Delta P=150 \mathrm{~Pa}, h_{c}=1.5 \mathrm{~mm}, E=1.6 \mathrm{MPa}$. 